\title{
Efficacy, safety and tolerability of aripiprazole in bipolar disorder: An updated systematic review and meta-analysis of randomized controlled trials
}

Dian-Jeng Li ${ }^{\mathrm{a}, \mathrm{b}, 1}$, Ping-Tao Tseng ${ }^{\mathrm{c}, \mathrm{d}, 1}$, Brendon Stubbs ${ }^{\mathrm{e}, \mathrm{f}}$, Che-Sheng $\mathrm{Chu}^{\mathrm{g}}$, Han-Yung Chang ${ }^{\mathrm{h}}$, Eduard Vieta $^{\mathrm{i}}$, Michele Fornaro ${ }^{\mathrm{j}, \mathrm{k}}$, Andre F. Carvalho ${ }^{1}$, Marco Solmi ${ }^{\mathrm{m}, \mathrm{t}}$, Nicola Veronese ${ }^{\mathrm{n}}$, Tien-Yu Chen ${ }^{\mathrm{o}, \mathrm{u}}$, Yen-Wen Chen ${ }^{\mathrm{p}}$, Pao-Yen Lin ${ }^{\mathrm{q}, \mathrm{r}, *}$, Philip Chik-keung $\mathrm{Chow}^{\mathrm{s}, * *}$

a Department of Addiction Science, Kaohsiung Municipal Kai-Syuan Psychiatric Hospital, Kaohsiung City, Taiwan

b Graduate Institute of Medicine, College of Medicine, Kaohsiung Medical University, Taiwan

c Department of Psychiatry, Tsyr-Huey Mental Hospital, Kaohsiung Jen-Ai's Home, Taiwan

${ }^{\mathrm{d}}$ WinShine Clinics in Specialty of Psychiatry, Kaohsiung City, Taiwan

e Physiotherapy Department, South London and Maudsley NHS Foundation Trust, London, UK

${ }^{\mathrm{f}}$ Health Service and Population Research Department, Institute of Psychiatry, Psychology and Neuroscience (IoPPN), King's College London, De Crespigny Park, London, $U K$

${ }^{g}$ Department of Psychiatry, Kaohsiung Veterans General Hospital, Kaohsiung City, Taiwan

${ }^{\text {h }}$ Kaohsiung Municipal Kai-Syuan Psychiatric Hospital, Kaohsiung, Taiwan

${ }^{\mathrm{i}}$ Bipolar Disorder Unit, Institute of Neuroscience, Hospital Clinic, University of Barcelona, IDIBAPS, CIBERSAM, Barcelona, Catalonia, Spain

${ }^{\mathrm{j}}$ New York State Psychiatric Institute (NYPSI), Columbia University, New York City, NY, USA

k Outpatient Unit on Treatment Resistant Psychosis, Department of Neuroscience, University School of Medicine Federico II, Naples, Italy

${ }^{1}$ Department of Clinical Medicine and Translational Psychiatry Research Group, Faculty of Medicine, Federal University of Ceará, Fortaleza, CE, Brazil

m Department of Neuroscience, University of Padova, Padova, Italy

${ }^{n}$ Geriatrics Division, Department of Medicine-DIMED, University of Padova, Padova, Italy

o Department of Psychiatry, Tri-Service General Hospital, Taipei, Taiwan

P Prospect Clinic for Otorhinolaryngology \& Neurology

${ }^{\mathrm{q}}$ Department of Psychiatry, Kaohsiung Chang Gung Memorial Hospital and Chang Gung University College of Medicine, Kaohsiung, Taiwan

${ }^{\mathbf{r}}$ Institute for Translational Research in Biomedical Sciences, Kaohsiung Chang Gung Memorial Hospital, Kaohsiung, Taiwan

s Department of Child and Adolescent Psychiatry, Kaohsiung Municipal Kai-Syuan Psychiatric Hospital, Kaohsiung City, Taiwan

${ }^{\mathrm{t}}$ Mental Health Institute for Clinical Research and Education on Medicine, I.R.E.M., Padua, Italy

${ }^{\mathbf{u}}$ School of Medicine, National Defense Medical Center, Taipei, Taiwan

\section{A R T I C L E I N F O}

\section{Keywords:}

Aripiprazole

Bipolar disorder

Efficacy

Tolerability

Meta-analysis

\begin{abstract}
A B S T R A C T
Numerous studies have investigated aripiprazole as a treatment for bipolar disorder (BD). therefore we conducted this comprehensive meta-analysis to investigate the efficacy and safety profile of aripiprazole in treating BD. Two authors conducted systematic searches of PubMed and ScienceDirect from inception until May 14th, 2017. Randomized controlled trials (RCTs) of people with BD who received aripiprazole were included. A total of 20 RCTs met the eligibility criteria, including two which investigated the efficacy of aripiprazole versus haloperidol (aripiprazole $=340$; haloperidol $=337$ ), three which compared aripiprazole versus lithium (aripiprazole $=208$; lithium $=212$ ), and 15 with multiple comparisons of aripiprazole versus a placebo (aripiprazole $=1923$; placebo $=1499$ ). Compared to a placebo, aripiprazole improved acute mania (Hedges' $g$ : $-0.299, p=0.001$ ) and psychosis (Hedges' $g:-0.296, p<0.001$ ) in the acute mania state, but did not improve depressive symptoms (Hedges' $g$ : $-0.127, p=0.054$ ) in the acute depressive state. Aripiprazole was associated with lower relapse rates in bipolar mania when used in combination versus a placebo in maintenance therapy (odds ratio: $0.522, p<0.029$ ). Aripiprazole was also associated with higher levels of high density lipoprotein, lower dropout rates, but no difference in extrapyramidal symptoms in the maintenance phase versus a placebo or in comparison with other medications (haloperidol or lithium). Our results suggest that aripiprazole
\end{abstract}

\footnotetext{
* Correspondence to: Pao-Yen Lin, Department of Psychiatry, Kaohsiung Chang Gung Memorial Hospital, 123, Dapi Road, Niaosong District, Kaohsiung City 833, Taiwan.

*** Correspondence to: Philip Chik-keung Chow, Department of Child and Adolescent Psychiatry, Kaohsiung Municipal Kai-Syuan Psychiatric Hospital, 130, Kaixuan 2nd Road, Lingya District, Kaohsiung City 802, Taiwan.

E-mail addresses: py1029@adm.cgmh.org.tw (P.-Y. Lin), py1029@cloud.cgmh.org.tw (P.C.-k. Chow).

${ }^{1}$ Contributed equally as first authors
} 
is effective and safe in treating bipolar mania. Further trials are necessary to evaluate the efficacy and tolerability versus other medications.

\section{Introduction}

Bipolar disorder (BD) affects approximately $2.4 \%$ of the general population (Merikangas et al., 2011) and is easily misdiagnosed or under-diagnosed (Angst, 2006). BD is associated with a greatly impaired quality of life, increased physical health burden (Vancampfort et al., 2016, 2015) and disability (Hirschfeld et al., 2003; Yatham et al., 2004). Moreover, BD can impact employment (Reed et al., 2010) and lead to lower self-esteem (Nilsson et al., 2010) and reduced social interaction (Judd and Akiskal, 2003). Furthermore, approximately 23\% of patients with BD report a history of suicide attempts (Kattimani et al., 2016).

BD has a complicated, multifactorial etiology including genetic, neuro-endocrine, and environmental factors (Craddock and Sklar, 2013). Pharmacological therapy is often the first-line treatment for BD, followed by psychological (Oud et al., 2016) and psychosocial interventions (Goodwin et al., 2008). In addition to lithium and anticonvulsants (van der Loos et al., 2011; Yildiz et al., 2015), antipsychotic agents have also shown promising efficacy for bipolar mania (Yildiz et al., 2011) and depression (Goodwin et al., 2016).

Aripiprazole, a novel antipsychotic agent combining partial agonist activity at dopamine-2 (D2), dopamine-3 (D3), and serotonin-1A (5HT1A) receptors with antagonist activity at serotonin-2A (5-HT2A) and D2 receptors (Burris et al., 2002; Jordan et al., 2002). It has shown beneficial effects in patients with schizophrenia and possibly in mood disorders including BD, including good tolerability in patients with schizophrenia (Oya et al., 2015), good efficacy in patients with acute mania (Fountoulakis et al., 2011; Young et al., 2009), and good efficacy in preventing relapses (Marcus et al., 2011), although there is limited evidence regarding bipolar depression (Vieta et al., 2010). Aripiprazole is known to have a beneficial metabolic profile, which is an important consideration given that these patients are at an increased risk of cardiometabolic disorders (Vancampfort et al., 2016, 2015), although it may be associated with akathisia.

Two previous meta-analyses (Brown et al., 2013; Meduri et al., 2016) investigated the efficacy or safety profile of aripiprazole. Brown et al. (2013) discussed the efficacy and adverse reactions in BD; however, the authors only addressed the effects of treatment with regards to episodes of mania without considering the depression or maintenance phase, and their search only included trials before 2013. Furthermore, previous analysis of adverse reactions has contained less than three trials, precluding the ability to make definitive conclusions (Davey et al., 2011). Another more recent meta-analysis (Meduri et al., 2016) included 16 trials and observational studies of $\mathrm{BD}$, however their analysis focused on the severity of changes in mania and response rates, and did not include subgroup analyses for depression, remission rates or relapse rates. Following these two meta-analyses, another two preliminary meta-analyses have also been published (Dundar et al., 2016; Lindstrom et al., 2017). Of them, the meta-analysis by Dundar et al. (2016) focused on pharmacologic treatment for acute agitation but not regular treatment. Their results revealed that olanzapine was superior to haloperidol, and that no other treatment, including aripiprazole, was more effective than any other (Dundar et al., 2016). On the other hand, the meta-analysis by Lindstrom et al. (2017), focused on the treatment effect of second-generation antipsychotics in the maintenance phase, and found that aripiprazole was beneficial in preventing relapses (Lindstrom et al., 2017). However, although their results showed statistical significance, the results for aripiprazole were based on only two datasets, thereby limiting the strength of their meta-analysis (Davey et al., 2011).
Given these gaps in the literature, we conducted this comprehensive systematic review and meta-analysis to investigate the efficacy and safety profile of aripiprazole in the treatment of $\mathrm{BD}$, specifically focusing on sub-group analyses of depression, laboratory data, adverse reactions, and preventive efficacy of mood episodes including relapse rates.

\section{Method and materials}

The current meta-analysis was conducted according to the Preferred Reporting Items for Systematic Reviews and Meta-Analyses (PRISMA) statement (Liberati et al., 2009) (Supplementary Table 1) following a pre-specified but unpublished protocol. This meta-analysis met the requirements of the Institutional Review Board of Tri-Service General Hospital (TSGHIRB: B-105-12).

\subsection{Inclusion criteria}

The inclusion criteria were: (1) published randomized controlled trials (RCTs) exploring the efficacy of aripiprazole as monotherapy or combination therapy versus a placebo or other antipsychotic medication; (2) articles including patients with the diagnosis of BD with either manic/mixed or depressed episodes based on the Diagnostic and Statistical Manual of Mental Disorders (DSM) criteria or International Classification of Diseases (ICD) codes; and (3) articles that were clinical trials including adult and adolescent populations, for whom aripiprazole has been approved to treat BD by the Food and Drug Administration (FDA) in the USA and the European Medicines Agency (EMA) in the EU. No limit was set for the length of study follow-up. The exclusion criteria were: (1) articles that were not controlled intervention studies; and (2) animal studies.

\subsection{Database searches and identification of eligible papers}

Two independent authors searched PubMed and ScienceDirect using the keywords (aripiprazole) AND (bipolar disorder OR mania OR depress) from inception to May 14th, 2017 with the limitations of "humans; clinical trial" for PubMed and "bipolar disorder/antipsychotic; journal article" for ScienceDirect. In addition, the reference lists of review articles relevant to this topic were manually searched to identify potentially eligible papers (Arbaizar et al., 2009; Biederman et al., 2005; Brown et al., 2013; Fountoulakis et al., 2009, 2011; McKeage, 2014; Meduri et al., 2016; Miura et al., 2014; Perlis, 2007, 2006; Scherk et al., 2007; Smith et al., 2007; Taylor, 2003; Vieta et al., 2010; Yatham et al., 2013; Yildiz et al., 2015).

After completing the searches, duplicate studies were removed, and two independent authors screened the titles and abstracts for eligibility. A list of potentially eligible studies was developed by consensus, and the full texts were assessed by the two authors. Both authors then applied the eligibility criteria and developed a final list of studies to be included. A third reviewer was available for mediation in the event of any inconsistencies.

\subsection{Methodological quality appraisal}

The methodological quality of the included studies was determined by two authors using the Jadad scale (Jadad et al., 1996). In brief, the Jadad score was calculated for each study and included three categories of study quality: randomization, blindness, and withdrawals and dropouts. The Jadad score ranged from zero (poor quality) to five (high 
quality).

\subsection{Primary outcomes}

The primary outcomes were differences in changes of measures of mania, depression, relapse rates, or general severity as measured using the Clinical Global Impressions Scale-Severity (CGI-S) from pre-treatment to post-treatment between aripiprazole and a placebo or other medications (haloperidol or lithium). The outcomes of interest had to be recorded using a validated scale such as the Hamilton Rating Scale for Depression (17-items) (HAM-D-17) (Williams, 1988) or Montgomery-Åsberg Depression Rating Scale (MADRS) (Montgomery and Asberg, 1979) for depressive symptoms, and Young Mania Rating Scale (YMRS) for mania symptoms (Young et al., 1978).

\subsection{Secondary outcomes}

The secondary outcomes of interest included response rates, remission rates, drop-out rates, rates of discontinuation of trials due to side effects, cognitive subscales of the Positive and Negative Syndrome Scale (PANSS), and the incidence of any adverse reactions. Other measurements of disease severity including the PANSS (Kay et al., 1987) for psychotic features, and CGI-S (Busner and Targum, 2007) for mania or depression were also recorded.

Response was defined as $\geq 50 \%$ reduction from baseline in YMRS total score (Jeong et al., 2012) or $\geq 50 \%$ decrease from baseline in MADRS total score (Thase et al., 2008). Remission was defined as a MADRS total score $\leq 8$ (Thase et al., 2008), YMRS total score $\leq 12$ or CGI-S $\leq 2$ (El Mallakh et al., 2010; Findling et al., 2009). Relapse was defined as discontinuation of the study due to a lack of efficacy (Keck et al., 2007), the need for hospitalization (Carlson et al., 2012; Jeong et al., 2012), YMRS total score $\geq 18$ or MADRS total score $\geq 18$ or $\geq 4$ point increase from baseline (El-Mallakh et al., 2012), YMRS total score $>14$ and a MADRS total score $\leq 16$ for a relapse of a manic episode, a YMRS total score $>14$ and a MADRS total score $>16$ for a relapse of a mixed episode, and a YMRS total score $\leq 14$ and a MADRS total score $>16$ for a relapse of a depressive episode (Thase et al., 2008).

\subsection{Data extraction and management}

Two independent authors extracted data from the eligible studies into a database. The variables of interest included mean age (years), age at onset, gender, duration of illness, treatment duration, dosage of prescribed aripiprazole, education, marriage status, occupation, ethnicity (Caucasian, Africa American, Hispanic, Asian, or Native America), Jadad score (Jadad et al., 1996), and all primary and secondary outcomes as listed above. When data were not available in the articles, we contacted the corresponding authors twice over a monthlong period in an attempt to acquire the variables of interest.

\subsection{Meta-analysis}

Under the presumed heterogeneity of the sample populations among all of the recruited studies, the data were analyzed using random-effects meta-analysis models rather than fixed effect models (Borenstein et al., 2010) with Comprehensive Meta-Analysis software, version 3 (Biostat, Englewood, NJ). Continuous outcomes were analyzed by calculating the effect sizes (ESs) as Hedges' $g$ and 95\% confidence intervals ( $95 \% \mathrm{CIs}$ ) comparing outcomes between aripiprazole and a placebo or other psychotropic medications. Odds ratios (ORs) and 95\% CIs were calculated for dichotomous data. When measuring the efficacy with regards to psychotic features, total PANSS scores were included into the analysis for a more complete evaluation, if the study provided both total PANSS and PANSS scores of positive symptoms. Data on adverse events were also pooled across studies and compared versus a placebo where possible.

A two-tailed $p$ value of $<0.05$ was considered to be statistically significant. Heterogeneity was assessed using the $\mathrm{Q}$ statistic to evaluate the dispersion of the true effect among the recruited studies (Higgins et al., 2003). Publication bias was evaluated by visual inspection of funnel plots and Egger's regression tests (Egger et al., 1997). In cases of publication bias, the trim and fill test was conducted to impute potential missing trials and re-calculate the effect size (Duval and Tweedie, 2000). Finally, meta-regression and subgroup meta-analyses were conducted to investigate the effects of clinical variables as possible sources of heterogeneity. Meta-regression analyses were performed using the unrestricted maximum likelihood method only when data were available across more than five studies. The variables of interest for meta-regression were mean age, female gender, body mass index (BMI), treatment duration, dosage of prescribed medications, duration of illness, education, marriage status, occupation, ethnicity (Caucasian, Africa American, Hispanic, Asian, or Native America), drop-out rate, and Jadad score.

Subgroup meta-analysis was performed when at least three sets of data were available (Davey et al., 2011). Subgroup analyses included monotherapy or combination therapy, acute or maintained course, and different categories of treatment doses in order to clarify the efficacy in clinical practice.

\begin{tabular}{|c|c|}
\hline $\begin{array}{l}\text { Database search: PubMed ( } n=59 \text { ) } \\
\text { Keyword: (aripiprazole) AND (bipolar disorder OR } \\
\text { mania OR depress) } \\
\text { Limitation: humans, clinical trial } \\
\text { Date: date available to } 2017 / 5 / 14\end{array}$ & $\begin{array}{l}\text { Database search: ScienceDirect ( } n=345 \text { ) } \\
\text { Keyword: (aripiprazole) AND (bipolar disorder OR } \\
\text { mania OR depress) } \\
\text { Filter: bipolar disorder/antipsychotic; journal article } \\
\text { Date: date available to } 2017 / 5 / 14\end{array}$ \\
\hline$\downarrow$ & $\downarrow$ \\
\hline
\end{tabular}

Remove duplicates when screening titles and abstracts $(n=334)$

Potential studies retrieved for assessment of eligibility $(n=43)$

Studies excluded: Lack of adequate control $(n=12)$

Not pure bipolar disorder $(n=1)$

Lack of data for efficacy $(n=3)$

Duplicated studies $(n=7)$

Included articles in meta-analysis $(\mathbf{n = 2 0})$
Fig. 1. Flowchart of the current meta-analysis.

The databases used, the inclusion criteria, the search strategy and selection process of the current meta-analysis. 


\section{Results}

\subsection{Study selection}

In the initial search, 373 studies were identified after removing duplicates (59 from PubMed and 341 from ScienceDirect). After screening the titles/abstracts, 43 full-text articles were assessed for eligibility, of which 22 were excluded (Fig. 1 and Supplementary Table 2). Therefore, 20 articles were eligible for the current metaanalysis (Carlson et al., 2012; El-Mallakh et al., 2012, 2010; Findling et al., 2013, 2009, 2012; Jeong et al., 2012; Kanba et al., 2014; Keck et al., 2007, 2003, 2009; Muzina et al., 2008; Quante et al., 2010; Sachs et al., 2006; Thase et al., 2008; Tramontina et al., 2009; Vieta et al., 2005, 2008; Woo et al., 2011; Young et al., 2009) (Table 1).

Among the 20 eligible articles, two investigated the efficacy of aripiprazole monotherapy in comparison with haloperidol (Vieta et al.,
2005; Young et al., 2009) (aripiprazole participants = 340; haloperidol participants $=337$ ). One article (Keck et al., 2009) compared aripiprazole monotherapy and lithium in the acute phase of illness (aripiprazole $=155$; lithium $=160$ ), another article (El-Mallakh et al., 2012) compared aripiprazole monotherapy versus lithium in the maintenance stage (aripiprazole $=25$; lithium $=38$ ), and another article (Jeong et al., 2012) investigated the combination of aripiprazole with valproic acid versus haloperidol with valproic acid (aripiprazole $=28$; haloperidol $=14$ ). The remaining 15 articles (Carlson et al., 2012; El Mallakh et al., 2010; Findling et al., 2013, 2009, 2012; Kanba et al., 2014; Keck et al., 2007, 2003; Muzina et al., 2008; Quante et al., 2010; Sachs et al., 2006; Thase et al., 2008; Tramontina et al., 2009; Vieta et al., 2008; Woo et al., 2011) compared aripiprazole monotherapy/combination therapy with a placebo in the acute or maintenance stage (aripiprazole $=1923$; placebo $=1499$ ).

Table 1

Summary of characteristics of studies in current meta-analysis.

\begin{tabular}{|c|c|c|c|c|c|c|c|c|c|}
\hline Study & Criteria & $\begin{array}{l}\text { Diagnosis/mood } \\
\text { state }\end{array}$ & Comparison & $\mathrm{N}$ & Dropout (\%) & $\begin{array}{l}\text { Gender ( } \% \\
\text { female) }\end{array}$ & Age & Phase & Country \\
\hline \multirow[t]{2}{*}{ Keck et al. (2003) } & \multirow[t]{2}{*}{ DSM-IV } & \multirow[t]{2}{*}{ BD-I, manic/mixed } & Aripiprazole & 130 & 58.0 & 55.0 & 40.5 & \multirow[t]{2}{*}{ Acute } & \multirow[t]{2}{*}{ USA } \\
\hline & & & Placebo & 132 & 79.0 & 58.0 & 40.5 & & \\
\hline \multirow[t]{2}{*}{ Vieta et al. (2005) } & \multirow[t]{2}{*}{ DSM-IV } & \multirow[t]{2}{*}{ BD-I, manic/mixed } & Aripiprazole & 175 & 49.4 & 56.6 & 42.6 & \multirow[t]{2}{*}{ Acute } & \multirow{2}{*}{$\begin{array}{l}\text { Multiple } \\
\text { country }\end{array}$} \\
\hline & & & Haloperidol & 172 & 71.8 & 66.9 & 41.0 & & \\
\hline \multirow[t]{2}{*}{ Sachs et al. (2006) } & \multirow[t]{2}{*}{ DSM-IV } & \multirow[t]{2}{*}{ BD-I, manic/mixed } & Aripiprazole & 137 & 45.0 & 50.0 & 37.3 & \multirow[t]{2}{*}{ Acute } & \multirow[t]{2}{*}{ USA } \\
\hline & & & Placebo & 135 & 48.0 & 53.0 & 40.4 & & \\
\hline \multirow{2}{*}{ Keck et al. (2007) } & \multirow[t]{2}{*}{ DSM-IV } & \multirow{2}{*}{ BD-I } & Aripiprazole & 77 & 91.0 & 62.0 & 39.0 & \multirow[t]{2}{*}{ Maintenance } & \\
\hline & & & Placebo & 81 & 92.8 & 72.0 & 40.3 & & country \\
\hline Thase et al. (2008) - & DSM-IV & BD-I, depressed & Aripiprazole & 186 & 46.8 & 62.0 & 39.0 & Acute & USA \\
\hline study A & & & Placebo & 188 & 35.1 & 63.0 & 39.0 & & \\
\hline Thase et al. (2008) - & DSM-IV & BD-I, depressed & Aripiprazole & 187 & 41.2 & 60.0 & 41.0 & Acute & USA \\
\hline study B & & & Placebo & 188 & 29.8 & 60.0 & 40.0 & & \\
\hline Muzina et al. (2008) & DSM-IV & BD-I, rapid cycling & Aripiprazole & 14 & 79.0 & 64.3 & 37.6 & Maintenance & USA \\
\hline & & & Placebo & 14 & 100.0 & 71.4 & 38.8 & & \\
\hline Vieta et al. (2008) & DSM-IV & BD-I, manic/mixed & Aripiprazole $+\mathrm{Li}$ or Val & 253 & $\mathrm{n} / \mathrm{a}$ & 52.0 & 42.2 & Acute & Multiple \\
\hline & & & Placebo $+\mathrm{Li}$ or Val & 131 & & 58.0 & 41.7 & & country \\
\hline Keck et al. (2009) & DSM-IV & BD-I, manic/mixed & Aripiprazole & 155 & 20.0 & 49.0 & 39.6 & Acute & USA \\
\hline & & & $\mathrm{Li}$ & 160 & 15.0 & 48.0 & 39.6 & & \\
\hline & & & Placebo & 165 & 19.0 & 48.0 & 39.8 & & \\
\hline Findling et al. (2009) & DSM-IV & BD-I, manic/mixed & Aripiprazole $10 \mathrm{mg}$ & 98 & 14.3 & 46.9 & 13.7 & Acute & USA \\
\hline & & & Aripiprazole $30 \mathrm{mg}$ & 99 & 22.2 & 48.5 & 13.3 & & \\
\hline & & & placebo & 99 & 23.2 & 43.4 & 13.3 & & \\
\hline Tramontina et al. (2009) & DSM-IV & BD-I, manic/mixed & Aripiprazole & 18 & 5.6 & 66.7 & 11.7 & Acute & Brazil \\
\hline & & & Placebo & 25 & 4.0 & 44.0 & 12.2 & & \\
\hline Young et al. (2009) & DSM-IV & BD-I, manic/mixed & Aripiprazole & 167 & 43.1 & 57.0 & 40.5 & Acute & Multiple \\
\hline & & & haloperidol & 165 & 42.4 & 56.0 & 41.6 & & country \\
\hline & & & Placebo & 153 & 45.1 & 54.0 & 40.2 & & \\
\hline Quante et al. (2010) & DSM-IV & BD-I or II, depressed & Aripiprazole $+(\mathrm{Li}$ or Val) & 12 & $\mathrm{n} / \mathrm{a}$ & 45.4 & 53.6 & Acute & Germany \\
\hline & & & + Citalopram & 11 & & 50.0 & 48.2 & & \\
\hline & & & Placebo $+(\mathrm{Li}$ or Val $)+$ Citalopram & & & & & & \\
\hline El Mallakh et al. (2010) & DSM-IV & BD-I, manic/mixed & Aripiprazole $15 \mathrm{mg}$ & 131 & 57.0 & 50.0 & 39.3 & Acute & Multiple \\
\hline & & & Aripiprazole $30 \mathrm{mg}$ & 136 & 60.0 & 54.0 & 41.4 & & country \\
\hline & & & Placebo & 134 & 60.0 & 51.0 & 40.6 & & \\
\hline Woo et al. (2011) & DSM-IV & BD-I, manic/mixed & Aripiprazole + Val & 40 & 42.5 & 67.5 & 38.3 & Maintenance & Korea \\
\hline & & & Placebo + Val & 43 & 41.9 & 55.8 & 38.3 & & \\
\hline El-Mallakh et al. (2012) & DSM-IV & BD-I, manic/mixed & Aripiprazole & 25 & 75.0 & 60.0 & 37.2 & Maintenance & USA \\
\hline & & & $\mathrm{Li}$ & 38 & 65.8 & 50.0 & 41.2 & & \\
\hline Carlson et al. (2012) & DSM-IV & BD-I, manic/mixed & Aripiprazole + Lamotrigine & 178 & 63.5 & 67.4 & 39.6 & Maintenance & USA \\
\hline & & & Placebo + Lamotrigine & 173 & 69.4 & 62.4 & 38.6 & & \\
\hline Jeong et al. (2012) & DSM-IV & BD-I, manic/mixed & Aripiprazole + Val & 28 & 7.1 & 67.9 & 37.2 & Acute & Korea \\
\hline & & & Haloperidol + Val & 14 & 7.1 & 57.1 & 36.1 & & \\
\hline Findling et al. (2012) & DSM-IV & BD-I or II & Aripiprazole + other & 30 & 80.0 & 37.0 & 7.1 & Maintenance & USA \\
\hline & & & psychostimulant & 30 & 100.0 & 23.0 & 6.7 & & \\
\hline & & & Placebo + other psychostimulant & & & & & & \\
\hline Findling et al. (2013) & DSM-IV & BD-I, manic/mixed & Aripiprazole $10 \mathrm{mg}$ & 75 & 54.7 & $\mathrm{n} / \mathrm{a}$ & 13.6 & Maintenance & USA \\
\hline & & & Aripiprazole $30 \mathrm{mg}$ & 71 & 69.0 & & 13.1 & & \\
\hline & & & Placebo & 64 & 81.3 & & 13.3 & & \\
\hline Kanba et al. (2014) & DSM-IV & BD-I, manic/mixed & Aripiprazole & 128 & 43.8 & 57.4 & 37.5 & Acute & Multiple \\
\hline & & & Placebo & 130 & 50.8 & 60.0 & 37.8 & & country \\
\hline
\end{tabular}

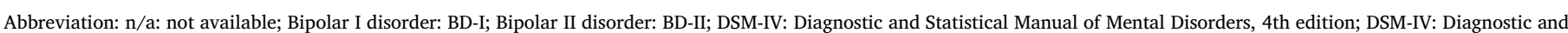
Statistical Manual of Mental Disorders, 4th edition; n/a: not applicable; Li: lithium; Val: valproate. 
A
Study name

\begin{tabular}{|c|c|c|c|c|}
\hline & $\begin{array}{c}\text { Hedges' } \\
g\end{array}$ & $\begin{array}{r}\text { Lower } \\
\text { limit }\end{array}$ & $\begin{array}{c}\text { Upper } \\
\text { limit }\end{array}$ & $p$-Value \\
\hline Findling, R.L. (2009) $10 \mathrm{mg}$ & -0.253 & -0.532 & 0.027 & 0.076 \\
\hline Findling, R.L. (2009) $30 \mathrm{mg}$ & -0.132 & -0.410 & 0.146 & 0.351 \\
\hline Sachs, G. (2006) & -0.238 & -0.476 & -0.000 & 0.050 \\
\hline Tramontina, S. (2009) & -0.165 & -0.761 & 0.431 & 0.588 \\
\hline Young, A.H. (2009) & 0.059 & -0.160 & 0.278 & 0.596 \\
\hline ve & -0.127 & -0.257 & 0.002 & 0.054 \\
\hline
\end{tabular}

Hedges' $g$ and $95 \% \mathrm{Cl}$

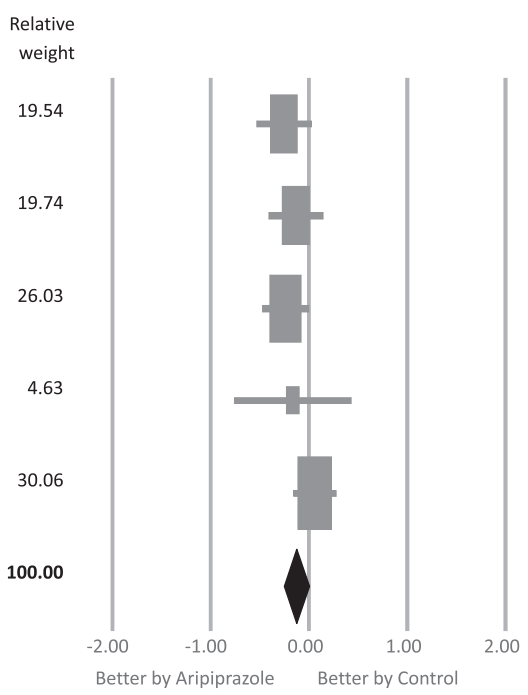

B

Study name

\begin{tabular}{|c|c|c|c|c|}
\hline & \multirow[b]{2}{*}{ Hedges' } & \\
\hline & & Lower & Upper & $p$-Value \\
\hline & $g$ & limit & limit & \\
\hline El Mallakh, R.S. (2010) $15 \mathrm{mg}$ & 0.010 & -0.230 & 0.250 & 0.936 \\
\hline El Mallakh, R.S. (2010) $30 \mathrm{mg}$ & -0.060 & -0.298 & 0.178 & 0.619 \\
\hline Findling, R.L. (2009) 10 mg & -0.564 & -0.848 & -0.280 & 0.000 \\
\hline Findling, R.L. (2009) 30 mg & -0.473 & -0.754 & -0.192 & 0.001 \\
\hline Sachs, G. (2006) & -0.377 & -0.617 & -0.138 & 0.002 \\
\hline Tramontina, S. (2009) & -0.735 & -1.349 & -0.120 & 0.019 \\
\hline Young, A.H. (2009) & -0.217 & -0.436 & 0.003 & 0.053 \\
\hline Overall & -0.299 & -0.476 & -0.123 & 0.001 \\
\hline
\end{tabular}

C

Study name

$\underline{\text { Statistics for each study }}$

Hedges' Lower Upper

$g \quad$ limit limit

$p$-Value

Findling, R.L. (2013) $10 \mathrm{mg} \quad-0.569 \quad-0.908 \quad-0.231 \quad 0.001$

Findling, R.L. (2013) $30 \mathrm{mg}$

$-0.57$

Keck, P.E. (2007)

$-0.332$

$-0.644$

$-0.019$

0.038

Overall

$\begin{array}{llll}-0.483 & -0.674 & -0.292 & 0.000\end{array}$
37.25

100.00

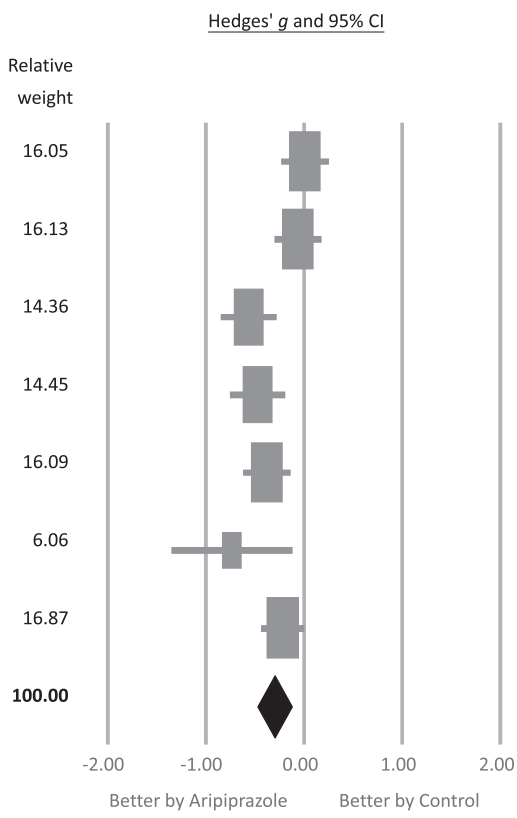

Hedges' $g$ and $95 \% \mathrm{Cl}$

Relative

weight

31.79

30.96

37.25
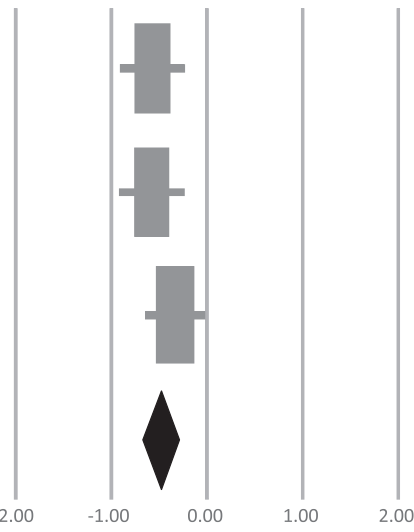

Fig. 2. (A) Forest plot of the meta-analysis of differences in changes in depressive symptoms in patients receiving aripiprazole and a placebo in acute bipolar depression; (B) forest plot of the meta-analysis of differences in changes in manic symptoms in patients receiving aripiprazole and a placebo in acute bipolar mania; (C) forest plot of the meta-analysis of differences in changes in the general severity in patients with bipolar disorder receiving aripiprazole and a placebo in the maintenance stage.

(A) There were no significant differences between changes in depressive symptoms between the patients receiving aripiprazole or a placebo in acute bipolar depression (Hedges' $g=-0.127,95 \% \mathrm{CI}=-0.257$ to $0.002, p=0.054$ ); (B) There was a significant improvement in manic symptoms in the patients receiving aripiprazole than those receiving a placebo in acute bipolar mania (Hedges' $g=-0.299$, 95\% $\mathrm{CI}=-0.476$ to $-0.123, p=0.001$ ). (C) There was a significant improvement in the general severity in patients with bipolar disorder receiving aripiprazole than in those receiving a placebo in the maintenance stage (Hedges' $g=-0.483,95 \% \mathrm{CI}=-0.674$ to -0.292 , $p<0.001$ ).

Better by Aripiprazole Better by Control 


\subsection{Methodological quality of the included studies}

Across the 20 studies, the average Jadad score was 3.35 with a standard deviation (SD) of 0.49 (Supplementary Table 3).

\subsection{Meta-analysis investigating the effect of aripiprazole on BD compared to a placebo or other medication}

3.3.1. Meta-analysis comparing the treatment efficacy of aripiprazole monotherapy and a placebo in the acute stage of $B D$

3.3.1.1. Primary outcome: comparing treatment efficacy for depression and mania

3.3.1.1.1. Treatment efficacy for depression. Across four articles (Findling et al., 2009; Sachs et al., 2006; Tramontina et al., 2009; Young et al., 2009), there was no significant difference in treatment effect between aripiprazole monotherapy (case number, $n=519$ in five comparative arms) and a placebo ( $n=412$ in four arms) for the acute stage of bipolar depression (Hedges' $g$ : $-0.127,95 \%$ CI: -0.257 to $0.002, p=0.054$, RCTs $=4$ with five datasets) (Fig. 2A). There was no significant heterogeneity $(\mathrm{Q}$ value $=4.41, \quad \mathrm{df}=4, \quad p=0.353$; $I^{2}=9.287 \%$, tau $=0.046$ ) or publication bias according to Egger's test ( $t=0.512, \mathrm{df}=3,2$-tailed $p=0.644)$. Following a sensitivity test and removal of the study by Young et al. (2009), aripiprazole was found to be more effective in treating depression versus a placebo (Hedges' $g$ : $-0.208,95 \%$ CI: -0.355 to $-0.061, p=0.006$ ).

We did not perform further subgroup meta-analysis of trials with adults only as fewer than three datasets were available (Sachs et al., 2006; Young et al., 2009). We divided the trials into two categories by daily dosage ( $<20 \mathrm{mg} /$ day and $>20 \mathrm{mg} /$ day) to evaluate whether or not there was a dose-dependent effect. Only two studies used a dose of $<20 \mathrm{mg}$ /day, thus precluding meta-analysis (Findling et al., 2009; Tramontina et al., 2009). Across three RCTs, no significant difference between aripiprazole ( $n=403$ in three arms) and placebo ( $n=387$ in three arms) was noted in the $>20 \mathrm{mg}$ /day group (Findling et al., 2009; Sachs et al., 2006; Young et al., 2009) (Hedges' g: - 0.097, 95\% CI: -0.279 to $0.086, p=0.299$ ).

Meta-regression analysis showed that age, female sex, dosage of aripiprazole, ethnicity (Caucasian), and Jadad scores (randomization, blind, total) were all non-significant (data not shown, available on request).

3.3.1.1.2. Treatment efficacy and relapse rates for mania. To determine the efficacy for mania, five articles (El Mallakh et al., 2010; Findling et al., 2009; Sachs et al., 2006; Tramontina et al., 2009; Young et al., 2009) were eligible for the analysis. Aripiprazole monotherapy ( $n=786$ in seven arms) was significantly superior to placebo ( $n=546$ in five arms) in treating mania (Hedges' $g$ : -0.299 , 95\% CI: -0.476 to $-0.123, p=0.001$ ) (Fig. 2B). Egger's regression test showed no significant publication bias $(t=1.519, \mathrm{df}=5$, 2-tailed $p=0.189$ ); however, heterogeneity was significant ( $\mathrm{Q}$ value $=17.51$, $\mathrm{df}=6, \quad p=0.008 ; I^{2}=65.73 \%$, tau $=0.188$ ). With regards to sensitivity, the significance of the results did not change after removing any one of the recruited studies.

The results of subgroup meta-analysis of trials with adults only revealed no significant difference in the treatment effect on manic symptoms between aripiprazole and a placebo (Hedges' $g$ : -0.162 , 95\% CI: -0.328 to 0.003, $p=0.055$ ) (El Mallakh et al., 2010; Sachs et al., 2006; Young et al., 2009). However, after removing data from El Mallakh et al.'s study (El Mallakh et al., 2010) which included aripiprazole $15 \mathrm{mg}$ only (El Mallakh et al., 2010), the results showed a significantly better treatment effect on manic symptoms in the aripiprazole arms than in the placebo arms (Hedges' $g$ : $-0.218,95 \%$ CI: -0.392 to $-0.043, p=0.014)$. In addition, in the lower dose group (<20 mg/day) (El Mallakh et al., 2010; Findling et al., 2009; Tramontina et al., 2009), aripiprazole ( $n=247$ in three arms) was not effective compared with a placebo $(n=258$ in three arms) (Hedges' $g$ : $-0.386,95 \%$ CI: -0.859 to $-0.087, p=0.109$ ). However, in the higher dose group ( $>20 \mathrm{mg} /$ day) (El Mallakh et al., 2010; Findling et al., 2009; Sachs et al., 2006; Young et al., 2009), aripiprazole ( $n=539$ in four arms) was superior to a placebo in treating mania ( $n=521$ in four arms) (Hedges' $g$ : $-0.272,95 \%$ CI: -0.444 to $-0.101, p=0.002$ ).

It was possible to perform subgroup meta-analysis of studies of a shorter duration ( $<4$ weeks) (El Mallakh et al., 2010; Young et al., 2009), and the results revealed no significant difference between aripiprazole ( $n=434$ in three arms) and a placebo ( $n=287$ in two arms) (Hedges' $g$ : $-0.097,95 \%$ CI: -0.231 to $0.037, p=0.157$ ). There were insufficient data for studies of a longer treatment duration ( $>4$ weeks) since only one article (Tramontina et al., 2009) met the inclusion criteria.

For relapse rates of mania, three datasets from two articles (Thase et al., 2008; Young et al., 2009) revealed no significant difference (OR: 0.829 , 95\% CI: 0.407 to $1.688, p=0.605$ ) between aripiprazole ( $n=538$ in 3 arms) and a placebo $(n=529$ in three arms) without significant heterogeneity $(Q$ value $=0.718, \quad \mathrm{df}=2, \quad p=0.698$; $I^{2}<0.001 \%$, tau $\left.<0.001\right)$ but significant publication bias $(t$ value $=135.796, \mathrm{df}=1, p=0.005$ ). However, after the trim and fill test (with two potentially missing studies to the left of the mean), no change in the results of meta-analysis was noted (OR: 0.650, 95\% CI: 0.358 to $1.180, p=0.157)$. In addition, no change was noted in a sensitivity analysis after removing one study.

In meta-regression analysis, older age was positively correlated with a greater effect size (coefficient $=0.0137, p=0.0081$ ) in treatment efficacy for mania. No relationship was noted for other variables (female sex, status of BD (percentage of manic mood state, rapid-cycling, or mixed episodes), dosage of aripiprazole, and ethnicity (Caucasian, Hispanic).

\subsubsection{Secondary outcomes: other measurements of efficacy and adverse} reactions

3.3.1.2.1. Efficacy profile: response rates, remission rates, and other measurements of severity (CGI-S, PANSS). There were insufficient data to analyze response rates or remission rates for depression. In three articles which reported remission rates for mania (Findling et al., 2009; Tramontina et al., 2009; Young et al., 2009), aripiprazole was significantly more effective than a placebo (OR: 4.893 , 95\% CI: 1.373 to 17.432, $p=0.014)$ with significant heterogeneity (Q value $=25.721, \quad \mathrm{df}=3, \quad p<0.001 ; I^{2}=88.336 \%, \quad$ tau $\left.=1.201\right)$ with no significant publication bias $(t$ value $=2.344$, $\mathrm{df}=2$, $p=0.144)$. The significance of the results became non-significant after removing the dataset of Findling et al. (10 mg aripiprazole/day) (OR: 4.689, 95\% CI: 0.858 to $25.618, p=0.075$ ) (Findling et al., 2009) or Tramontina et al. (OR: $4.786,95 \%$ CI: 0.987 to $23.214, p=0.052$ ) (Tramontina et al., 2009). Response rates for mania were reported in five articles (El Mallakh et al., 2010; Findling et al., 2009; Sachs et al., 2006; Tramontina et al., 2009; Young et al., 2009), and aripiprazole was significantly better than a placebo (OR: $2.054,95 \%$ CI: 1.366 to 3.089, $p=0.001$ ) with significant heterogeneity $(\mathrm{Q}$ value $=21.062$, $\mathrm{df}=6, p=0.002 ; I^{2}=71.513 \%$, tau $=0.450$ ) but no significant publication bias ( $t$ value $=1.625, \mathrm{df}=5, p=0.165$ ). The results did not change after the removal of one study.

The CGI-S was used to estimate the general severity of illness for mania, depressed or mixed episodes across nine articles (El Mallakh et al., 2010; Findling et al., 2009; Kanba et al., 2014; Keck et al., 2003, 2009; Sachs et al., 2006; Thase et al., 2008; Tramontina et al., 2009; Young et al., 2009). After treatment, aripiprazole was associated with a greater improvement in CGI-S scores than a placebo (Hedges' $g$ : -0.322 , $95 \%$ CI: -0.418 to $-0.225, p<0.001$ ) without evidence of heterogeneity $\left(\mathrm{Q}\right.$ value $=16.678, \mathrm{df}=10, p=0.082 ; I^{2}=40.040 \%$, tau $=0.102)$ but with significant publication bias $(t$ value $=2.317$, $\mathrm{df}=9, p=0.046$ ). However, after the trim and fill test (with two potentially missing studies to the right of the mean), the results of the meta-analysis did not change (Hedges' $g$ : -0.293 , 95\% CI: -0.391 to 
$-0.195, p<0.001)$. The results did not change after the removal of one study.

In four articles (Kanba et al., 2014; Keck et al., 2009; Sachs et al., 2006; Young et al., 2009), aripiprazole was more effective than a placebo in improving psychotic features (Hedges' $g$ : $-0.296,95 \%$ CI: -0.411 to $-0.181, p<0.001)$. No significant heterogeneity was noted $\left(\mathrm{Q}\right.$ value $=0.101, \mathrm{df}=3, p=0.992 ; I^{2}<0.001 \%$, tau $<$ 0.001) although there was evidence of publication bias ( $t$ value $=12.390, \mathrm{df}=2, p=0.006$ ). However, the trim and fill test (with two potentially missing studies to the right of the mean) did not change the main result (Hedges' $g$ : -0.288 , 95\% CI: -0.393 to $-0.184, p<0.001$ ). No change in the result was noted after the removal of one study.

\subsubsection{Adverse outcomes and dropout rates.}

3.3.1.3.1. Metabolic profile: fasting glucose, BMI, body weight, high density lipoprotein (HDL), total cholesterol, triglyceride (TG), and increased appetite. Compared to a placebo, aripiprazole was associated with a lower risk of elevated fasting glucose (Hedges' g: 0.447, 95\% CI: 0.048 to $0.846, p=0.028$, RCTs $=2$ with three datasets), increased appetite (OR: $2.114,95 \%$ CI: 1.058 to $4.226, p=0.034$, RCTs $=2$ with four datasets), and total cholesterol (OR: 1.686, 95\% CI: 1.032 to 2.754 , $p=0.037$, RCTs $=2$ with three datasets). No significant differences were noted between aripiprazole and a placebo in changes in BMI (Hedges' $g$ : $0.170,95 \%$ CI: -0.017 to $0.357, p=0.074$, RCTs $=2$ with three datasets) and body weight (Hedges' $g$ : $0.051,95 \%$ CI: -0.109 to $0.210, p=0.535, \quad$ RCTs $=4$ with five datasets). Furthermore, aripiprazole did not affect levels of high density lipoprotein (HDL) (Hedges' $g$ : $-0.233,95 \%$ CI: -0.488 to $0.022, p=0.074$, RCTs $=2$ with three datasets) or TG (Hedges' $g$ : $0.082,95 \%$ CI: -0.064 to 0.228 , $p=0.273$, RCTs $=2$ with three datasets) compared to a placebo (Table 3).

3.3.1.3.2. Adherence profile: dropout rates and rates of discontinuation due to side effects. There was no significant difference in dropout rate due to any reason between aripiprazole and a placebo (OR: 0.923, 95\% CI: 0.723 to $1.178, p=0.521$, RCTs $=9$ with 12 datasets). In contrast, aripiprazole was associated with higher rates of discontinuation due to side effects compared to a placebo (OR: $1.551,95 \%$ CI: 1.155 to 2.082 , $p=0.004$, RCTs $=8$ with 11 datasets) (Table 3).

3.3.1.3.3. Gastro-intestinal profile (constipation, diarrhea, nausea, vomiting, dyspepsia). Aripiprazole was associated with higher rates of constipation (OR: $1.720,95 \%$ CI: 1.251 to $2.365, p=0.001$, RCTs $=6$ with nine datasets), nausea (OR: 1.816, 95\% CI: 1.427 to 2.310, $p<0.001$, RCTs $=7$ with 10 datasets), and vomiting (OR: 2.083, $95 \%$ CI: 1.354 to $3.203, p=0.001$, RCTs $=6$ with nine datasets) compared to a placebo. However, there were no significant differences in diarrhea (OR: $0.956,95 \%$ CI: 0.694 to $1.319, p=0.785$, RCTs $=5$ with seven datasets) and dyspepsia (OR: $1.444,95 \%$ CI: 0.891 to 2.339 , $p=0.136$, RCTs $=4$ with six datasets) between aripiprazole and a placebo (Table 3 ).

3.3.1.3.4. Other adverse events: agitation, akathisia, anxiety, dizziness, over-sedation, light headedness, headache, fatigue, insomnia, pain in the extremities, and profile of extrapyramidal symptoms (EPS and sialorrhea). Higher incidence rates of akathisia (OR: 5.104, 95\% CI: 3.733 to $6.980, p<0.001$, RCTs $=8$ with 11 datasets), anxiety (OR: $1.526,95 \%$ CI: 1.058 to $2.203, p=0.024$, RCTs $=4$ with six datasets), EPS (Hedges' g: $0.538,95 \%$ CI: 0.070 to $1.007, p=0.024$, RCTs $=4$ with five datasets), hyper-salivation (OR: 4.696 , 95\% CI: 1.535 to 14.369, $p=0.007$, RCTs $=2$ with three datasets), fatigue (OR: 2.272 , 95\% CI: 1.443 to $3.577, p<0.001$, RCTs $=2$ with four datasets), insomnia (OR: $1.496,95 \%$ CI: 1.028 to $2.177, p=0.035$, RCTs $=5$ with seven datasets), over-sedation (OR: $3.607,95 \%$ CI: 2.267 to 5.739 , $p<0.001$, RCTs $=5$ with seven datasets), and pain in the extremities (OR: $2.281,95 \%$ CI: 1.260 to $4.127, p=0.006$, RCTs $=2$ with three datasets) were observed with aripiprazole than with a placebo. However, there were no significant differences between aripiprazole and a placebo in dizziness (OR: $1.361,95 \%$ CI: 0.719 to 2.575 , $p=0.344$, RCTs $=2$ with four datasets), agitation (OR: $1.079,95 \%$ CI: 0.773 to $1.508, p=0.654$, RCTs $=3$ with four datasets), headache (OR: $1.029,95 \%$ CI: 0.857 to $1.235, p=0.762$, RCTs $=8$ with 11 datasets), and light headedness (OR: $1.108,95 \%$ CI: 0.737 to 1.666 $p=0.621$, RCTs $=3$ with four datasets) (Table 3 ).

3.3.2. Meta-analysis comparing the treatment efficacy of aripiprazole monotherapy and a placebo in the maintenance stage of $B D$

3.3.2.1. Primary outcome: rates of total relapse and general severity (CGI$S$ ). Data were available from three studies to analyze the treatment efficacy during the maintenance phase (Findling et al., 2013; Keck et al., 2007; Muzina et al., 2008). In two of the articles (Findling et al., 2013; Keck et al., 2007), aripiprazole ( $n=185$ in three arms) was significantly superior to a placebo ( $n=91$ in two arms) in reducing CGI-S (Hedges' $g$ : -0.483 , 95\% CI: -0.674 to $-0.292, p<0.001$ ) (Fig. 2C) without significant heterogeneity ( $Q$ value $=1.436, \mathrm{df}=2$, $p=0.488 ; I^{2}<0.001 \%$, tau $\left.<0.001\right)$ or publication bias $(t$ value $=9.461, \mathrm{df}=1, p=0.067)$. The results were unchanged after the removal of one study.

We could not perform further meta-analysis of total relapse rate in the maintenance stage of aripiprazole monotherapy and placebo monotherapy because only two studies contained relevant data (Keck et al., 2007; Muzina et al., 2008). In these studies, the total relapse rates were significantly lower in the aripiprazole group than in the placebo group in the study by Keck et al. (2007) (33\% in the aripiprazole group and $52 \%$ in the placebo group) (Keck et al., 2007), and in the study by Muzina et al. the time to relapse was significantly longer in the aripiprazole group than in the placebo group at week 100 (hazard ratio $=0.18, \log$-rank $p=0.017$ ) (Muzina et al., 2008).

\subsubsection{Secondary outcome: other measurements of efficacy and adverse} reactions

3.3.2.2.1. Metabolic profile: fasting glucose, body weight, HDL, total cholesterol, and TG. No significant differences were noted between treatment with aripiprazole and a placebo in fasting glucose (Hedges' g: $0.169,95 \%$ CI: -0.013 to $0.361, p=0.069$, RCTs $=3$ with four datasets), increase in body weight (OR: $2.228,95 \%$ CI: 0.856 to 5.801 , $p=0.101$, RCTs $=2$ with three datasets), change in total cholesterol (Hedges' $g$ : $0.179,95 \%$ CI: -0.156 to $0.514, p=0.295$, RCTs $=3$ with four datasets), and changes in TG (Hedges' $g$ : 0.013 , 95\% CI: -0.606 to $0.631, p=0.968$, RCTs $=3$ with four datasets). However, aripiprazole was associated with an increased level of HDL compared to a placebo (Hedges' $g:-0.710,95 \%$ CI: -1.165 to $-0.254, p=0.002$, difference in means $=-2.622,95 \% \mathrm{CI}:-4.370$ to -0.875 , RCTs $=3$ with four datasets) (Table 3).

3.3.2.2.2. Adherence profile: dropout rates, and rates of discontinuation due to side effects. Aripiprazole was associated with significantly higher rates of discontinuation of treatment due to side effects compared to a placebo (OR: 7.897, 95\% CI: 1.740 to $35.848, p=0.007$, RCTs $=3$ with four datasets). On the other hand, aripiprazole was associated with a significantly lower dropout rate compared to a placebo (OR: 0.417, 95\% CI: 0.249 to $0.696, p=0.001$, RCTs $=3$ with four datasets) (Table 3).

3.3.2.2.3. Gastro-intestinal profile: diarrhea, nausea, and dry mouth. Aripiprazole was associated with significantly higher rates of diarrhea (OR: $7.472,95 \%$ CI: 1.322 to $42.234, p=0.023$, RCTs $=2$ with three datasets), and dry mouth (OR: $5.801,95 \%$ CI: 1.473 to 22.839, $p=0.012$, RCTs $=3$ with four datasets) compared to a placebo (Table 3).

3.3.2.2.4. Other adverse events: akathisia, back pain, over-sedation, headache, tremor, EPS, and upper respiratory tract infection. Aripiprazole was associated with a significantly higher rate of akathisia (OR: 7.711, 95\% CI: 2.162 to $27.499, p=0.002$, RCTs $=3$ with four datasets) compared to a placebo. However, there were no significant differences in the rates of headache (OR: $1.501,95 \%$ CI: 0.853 to $2.641, p=0.159$, 
RCTs $=2$ with three datasets) and upper respiratory-tract infection (OR: $2.308,95 \%$ CI: 0.925 to $5.763, p=0.073$, RCTs $=2$ with three datasets) between aripiprazole and a placebo (Table 3).

3.3.3. Meta-analysis comparing the treatment efficacy of aripiprazole combination therapy and a placebo in the acute or maintenance stage of $B D$ 3.3.3.1. Primary outcome: relapse rates for mania. Only two articles compared aripiprazole in combination therapy in the acute phase of $\mathrm{BD}$ thus precluding meta-analysis (Quante et al., 2010; Vieta et al., 2008).

Three trials (Carlson et al., 2012; Findling et al., 2012; Woo et al., 2011) were eligible in the maintenance phase with 248 patients in three arms receiving aripiprazole and 246 in three arms receiving a placebo. Aripiprazole tended to have a lower mania relapse rate (OR: 0.522, 95\% CI: 0.291 to $0.937, p=0.029$ ) compared to a placebo without significant heterogeneity $(\mathrm{Q} \quad$ value $=1.254, \quad \mathrm{df}=2, \quad p=0.534$; $I^{2}<0.001 \%$, tau $<0.001$ ) or publication bias $(t$ value $=0.477$, $\mathrm{df}=1, p=0.717$ ). After removal of the study by Carlson et al. (2012) (OR: $0.453,95 \%$ CI: 0.107 to $1.926, p=0.284$ ) or Findling et al. (2012) (OR: $0.567,95 \%$ CI: 0.310 to $1.040, p=0.067$ ), the results were not significant.
3.3.3.2. Secondary outcome: other measurements of adverse reactions. In terms of side effect profiles, aripiprazole was associated with a significantly greater increase in total cholesterol (difference in means: $2.000,95 \%$ CI: 1.993 to $2.007, p<0.001$, RCTs $=3$ with three datasets). No significant differences were observed between aripiprazole and a placebo in changes in fasting glucose (difference in means: $-1.967,95 \%$ CI: -8.447 to $4.514, p=0.552$, RCTs $=3$ with three datasets), changes in TG (difference in means: $3.238,95 \% \mathrm{CI}$ : -8.162 to $14.638, p=0.578$, RCTs $=3$ with three datasets), incidence of headache (OR: $0.721,95 \%$ CI: 0.262 to 1.983 , $p=0.526$, RCTs $=3$ with three datasets) and dropout rate (OR: $0.748,95 \%$ CI: 0.381 to $1.468, p=0.398$, RCTs $=3$ with three datasets) (Table 3).

3.3.4. Meta-analysis comparing the treatment efficacy of aripiprazole monotherapy or combination therapy with other medications (lithium or haloperidol) in the acute or maintenance stage of $B D$

Meta-analysis comparing the treatment efficacy of aripiprazole monotherapy and other medications during the maintenance phase was not possible because only one article (El-Mallakh et al., 2012) contained

Table 2

Summary of comparison between current study and two recently meta-analysis on aripiprazole.

\begin{tabular}{|c|c|c|c|}
\hline Articles & Current & Brown et al. (2013) & Meduri et al. (2016) \\
\hline No. of included articles & 20 & 10 & 22 \\
\hline Open labeled trails & Not included & Not included & 5 \\
\hline RCCTs & 2 & 2 & 2 \\
\hline RPCTs & 20 & 9 & 15 \\
\hline End of search & January 23th, 2017 & July 31th, 2013 & June 30th, 2015 \\
\hline Mood states & Manic/mixed, depressed & Manic/mixed & Manic/mixed, depressed \\
\hline MA of acute phase & Included & Included & Included \\
\hline MA of maintenance phase & Included & $\mathrm{n} / \mathrm{a}$ & $\mathrm{n} / \mathrm{a}$ \\
\hline \multicolumn{4}{|l|}{ MA of efficacy (result) } \\
\hline $\begin{array}{l}\text { Changes of severity } \\
\text { (depression) }\end{array}$ & $\begin{array}{l}\text { NS (Arp vs. Pla, mono-tx in AP) } \\
\text { NS (Arp vs. Hal or Li, mono-tx in AP) }\end{array}$ & $\begin{array}{l}\text { NS }^{\text {a }} \text { (Arp vs. Pla, mono-tx) } \\
\text { NS }^{\text {a }} \text { (Arp vs. Hal or Li, mono-tx) }\end{array}$ & $\mathrm{n} / \mathrm{a}$ \\
\hline Changes of severity (mania) & $\begin{array}{l}\text { Favor Arp (Arp vs. Pla, mono-tx in AP) } \\
\text { n/a (Arp vs. Hal or Li, mono-tx) }\end{array}$ & $\begin{array}{l}\text { Favor Arp (Arp vs. Pla, mono-tx) } \\
\text { NS (Arp vs. Hal or Li, mono-tx) }\end{array}$ & $\begin{array}{l}\text { Favor Arp (Arp vs. Pla, } \\
\text { mono-tx) } \\
\text { NS (Arp vs. Hal or Li, } \\
\text { mono-tx) }\end{array}$ \\
\hline $\begin{array}{l}\text { Changes of severity } \\
\text { (psychotic features) }\end{array}$ & Favor Arp (Arp vs. Pla, mono-tx in AP) & $\begin{array}{l}\text { Favor Arp (Arp vs. Pla, mono-tx) } \\
\text { NS }^{\text {a }} \text { (Arp vs. Hal or Li, mono-tx) }\end{array}$ & $\mathrm{n} / \mathrm{a}$ \\
\hline Response rates & $\begin{array}{l}\text { Favor Arp in mania (Arp vs. Pla, mono-tx in AP) } \\
\text { NS (Arp vs. Hal or Li, mono-tx) }\end{array}$ & $\begin{array}{l}\text { Favor Arp in mania (Arp vs. Pla, mono-tx) } \\
\text { NS in mania (Arp vs. Hal or Li, mono-tx) }\end{array}$ & $\begin{array}{l}\text { Favor Arp in mania (Arp } \\
\text { vs. pla, mono-tx) } \\
\text { NS in mania (Arp vs. Hal } \\
\text { or Li, mono-tx) }\end{array}$ \\
\hline Remission rates & Favor Arp in mania (Arp vs. Pla, mono-tx in AP) & NS in mania (Arp vs. Pla, mono-tx) & $\mathrm{n} / \mathrm{a}$ \\
\hline Relapse rates & Favor Arp (Arp vs. Pla, com-tx in MP) & $\mathrm{n} / \mathrm{a}$ & $\mathrm{n} / \mathrm{a}$ \\
\hline CGI-S & $\begin{array}{l}\text { Favor Arp (Arp vs. Pla, mono-tx in AP) } \\
\text { Favor Arp (Arp vs. Pla, mono-tx in MP) } \\
\text { Favor Arp (Arp vs. Hal or Li, mono-tx in AP) }\end{array}$ & $\begin{array}{l}\text { Favor Arp in mania (Arp vs. Pla, mono-tx) } \\
\text { NS in depression (Arp vs. Pla, mono-tx) } \\
\text { Favor Arp overall }^{\text {b }} \text { (Arp vs. Pla, mono-tx) } \\
\text { NS in mania }{ }^{a} \text { (Arp vs. Hal or Li, mono-tx) } \\
\text { NS in depression }{ }^{\text {a }} \text { (Arp vs. Hal or Li, mono-tx) }\end{array}$ & $\mathrm{n} / \mathrm{a}$ \\
\hline \multicolumn{4}{|l|}{ MA of adverse drug reaction } \\
\hline Metabolic profile & $\begin{array}{l}\text { Increased appetite, Sugar AC, BMI, BW change, level of HDL, level } \\
\text { of TG }\end{array}$ & Weight gain & $\mathrm{n} / \mathrm{a}$ \\
\hline Adherences profile & Dropout rates, Dis SE & Dropout rates, Dis SE & $\mathrm{n} / \mathrm{a}$ \\
\hline Gastro-intestinal profile & Constipation, diarrhea, nausea vomiting, dyspepsia, dry mouth & $\begin{array}{l}\text { Nausea, dyspepsia, vomiting, constipation, } \\
\text { diarrhea }\end{array}$ & $\mathrm{n} / \mathrm{a}$ \\
\hline EPS & EPS, salivation, tremor & EPS, tremor & $\mathrm{n} / \mathrm{a}$ \\
\hline Other ADRs & $\begin{array}{l}\text { Agitation, akathisia, anxiety, dizziness over-sedation, light- } \\
\text { headedness, UTI, insomnia, headache, fatigue dyspnea, pain } \\
\text { extremities, back pain }\end{array}$ & $\begin{array}{l}\text { Hypertension } \\
\text { Akathisia, headache, anxiety, insomnia, light- } \\
\text { headedness, pain extremities, over-sedation }\end{array}$ & $\mathrm{n} / \mathrm{a}$ \\
\hline
\end{tabular}

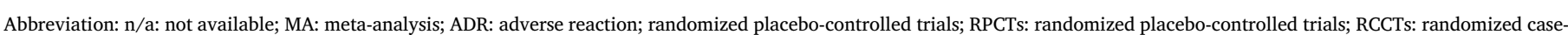

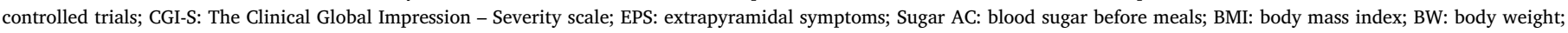

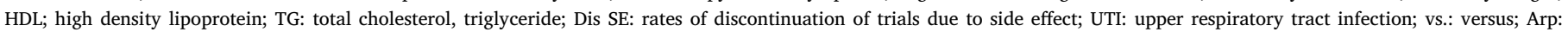
aripiprazole; Hal: haloperidol; Li: lithium; Pla: placebo; mono-tx: monotherapy; com-tx: combination therapy; AP: acute phase; MP: maintenance phase; NS: non-significance.

a Less than three trials.

${ }^{\mathrm{b}}$ Mania plus depression. 
sufficient relevant data. Another short trial (Jeong et al., 2012) did not have sufficient data for meta-analysis in the acute or maintenance phase of BD.

3.3.4.1. Primary outcome: treatment efficacy for depressed symptoms, general severity (CGI-S), response rates, and manic symptoms. Of three articles (Keck et al., 2009; Vieta et al., 2005; Young et al., 2009) with data of the acute stage, aripiprazole monotherapy ( $n=497$ in three arms) did not significantly differ from other medications (haloperidol $=337$ in two arms and lithium $=160$ in one arm) in the treatment efficacy of depressed symptoms during the acute phase (Hedges' $g$ : $-0.039,95 \%$ CI: -0.193 to $0.115, p=0.620$ ). No significant heterogeneity $(\mathrm{Q}$ value $=3.085, \quad \mathrm{df}=2, \quad p=0.214$; $I^{2}=35.173 \%$, tau $\left.=0.081\right)$ or publication bias $(t=0.2854, \mathrm{df}=1$, 2-tailed $p=0.823$ ) were observed. The results were unchanged after the removal of one study. Furthermore, aripiprazole was significantly better than the other medications (haloperidol or lithium) in CGI-S (Hedges' $g$ : $-0.191,95 \%$ CI: -0.315 to $-0.067, p=0.003$ ) without significant heterogeneity $(\mathrm{Q}$ value $=1.648, \quad \mathrm{df}=2, \quad p=0.439$; $I^{2}<0.001 \%$, tau $\left.<0.001\right)$ or publication bias $(t=0.044, \mathrm{df}=1$, 2-tailed $p=0.972)$. Three articles reported the efficacy for mania symptoms (Keck et al., 2009; Vieta et al., 2005; Young et al., 2009), in which aripiprazole showed no significant difference in response rates (OR: $1.271,95 \%$ CI: 0.647 to $2.496, p=0.486$ ) compared to haloperidol or lithium. Subgroup analysis by medication (haloperidol vs. aripiprazole and lithium vs. aripiprazole) could not be performed because of insufficient data (less than three RCTs).

3.3.4.2. Secondary outcome: other adverse reactions. There were no significant differences between aripiprazole and other medications (haloperidol or lithium) in akathisia (OR: $0.789,95 \%$ CI: 0.241 to 2.586, $p=0.696$, RCTs $=3$ with three datasets), dropout rate (OR: $0.812,95 \%$ CI: 0.375 to $1.759, p=0.598$, RCTs $=3$ with three datasets), rates of discontinuation due to side effects (OR: 0.710, 95\% CI: 0.212 to $2.378, p=0.578, \quad$ RCTs $=3$ with three datasets), symptoms of EPS (Hedges' $g$ : $-0.436,95 \%$ CI: -1.032 to 0.159 , $p=0.151$, RCTs $=3$ with three datasets), headache (OR: $1.079,95 \%$ CI: 0.748 to $1.555, p=0.685$, RCTs $=3$ with three datasets), and tremor (OR: $0.684,95 \%$ CI: 0.433 to $1.082, p=0.105$, RCTs $=3$ with three datasets) (Table 3).

\section{Discussion}

To the best of our knowledge, this is first meta-analysis to comprehensively investigate the efficacy tolerability, and adverse reactions to aripiprazole from the acute to maintenance stage within bipolar manic/mixed state to bipolar depression. Comparison to two recent meta-analyses (Brown et al., 2013; Meduri et al., 2016), our study provided more information on the analysis of adverse reactions and preventive efficacy as shown by relapse rates from bipolar mania to bipolar depression. The more recent search dates and stricter inclusion criteria (only RCTs in this meta-analysis) mean that the results of this meta-analysis are more up-to-date compared to the previous reports. The main differences between the current study and the two previous meta-analyses are listed in Table 2. It should be noted that two (Findling et al., 2009; Tramontina et al., 2009) of the included articles reported the efficacy of BD in adolescents. In addition, the dose-dependent responses and adverse reactions to antipsychotic drugs should

Table 3

Summary of comparison of adverse reactions in current meta-analysis.

\begin{tabular}{|c|c|c|c|c|}
\hline \multirow[t]{2}{*}{ Adverse reaction } & \multirow{2}{*}{$\begin{array}{l}\text { Acute phase } \\
\text { ARP monotherapy vs PLA }\end{array}$} & \multirow{2}{*}{$\begin{array}{l}\text { Maintenance phase } \\
\text { ARP monotherapy vs PLA }\end{array}$} & \multicolumn{2}{|l|}{ Acute/maintenance phase } \\
\hline & & & ARP combination therapy vs PLA & ARP combination therapy/monotherapy vs other Rx \\
\hline \multicolumn{5}{|l|}{ Metabolic profile } \\
\hline Fasting glucose & Worse by PLA & N.S. & N.S. & $\mathrm{n} / \mathrm{a}$ \\
\hline BMI & N.S. & $\mathrm{n} / \mathrm{a}$ & $\mathrm{n} / \mathrm{a}$ & $\mathrm{n} / \mathrm{a}$ \\
\hline BW & N.S. & N.S. & $\mathrm{n} / \mathrm{a}$ & $\mathrm{n} / \mathrm{a}$ \\
\hline HDL & N.S. & Worse by ARP & $\mathrm{n} / \mathrm{a}$ & $\mathrm{n} / \mathrm{a}$ \\
\hline T-chol & Worse by PLA & N.S. & Worse by ARP & $\mathrm{n} / \mathrm{a}$ \\
\hline TG & N.S. & N.S. & N.S. & $\mathrm{n} / \mathrm{a}$ \\
\hline Increased appetite & Worse by PLA & $\mathrm{n} / \mathrm{a}$ & $\mathrm{n} / \mathrm{a}$ & $\mathrm{n} / \mathrm{a}$ \\
\hline Adherences profile & & & & $\mathrm{n} / \mathrm{a}$ \\
\hline Dropout rate & N.S. & Worse by PLA & N.S. & N.S. \\
\hline Dis-side-effect & Worse by ARP & Worse by ARP & $\mathrm{n} / \mathrm{a}$ & N.S. \\
\hline Gastro-intestinal profile & & & & $\mathrm{n} / \mathrm{a}$ \\
\hline Constipation & Worse by ARP & $\mathrm{n} / \mathrm{a}$ & $\mathrm{n} / \mathrm{a}$ & $\mathrm{n} / \mathrm{a}$ \\
\hline Diarrhea & N.S. & Worse by ARP & $\mathrm{n} / \mathrm{a}$ & $\mathrm{n} / \mathrm{a}$ \\
\hline Nausea & Worse by ARP & $\mathrm{n} / \mathrm{a}$ & $\mathrm{n} / \mathrm{a}$ & $\mathrm{n} / \mathrm{a}$ \\
\hline Vomiting & Worse by ARP & $\mathrm{n} / \mathrm{a}$ & $\mathrm{n} / \mathrm{a}$ & $\mathrm{n} / \mathrm{a}$ \\
\hline Dyspepsia & N.S. & $\mathrm{n} / \mathrm{a}$ & $\mathrm{n} / \mathrm{a}$ & $\mathrm{n} / \mathrm{a}$ \\
\hline Dry mouth & $\mathrm{n} / \mathrm{a}$ & Worse by ARP & $\mathrm{n} / \mathrm{a}$ & $\mathrm{n} / \mathrm{a}$ \\
\hline Other profile & & & & $\mathrm{n} / \mathrm{a}$ \\
\hline Agitation & N.S. & $\mathrm{n} / \mathrm{a}$ & $\mathrm{n} / \mathrm{a}$ & $\mathrm{n} / \mathrm{a}$ \\
\hline Akathisia & Worse by ARP & Worse by ARP & $\mathrm{n} / \mathrm{a}$ & N.S. \\
\hline Anxiety & Worse by ARP & $\mathrm{n} / \mathrm{a}$ & $\mathrm{n} / \mathrm{a}$ & $\mathrm{n} / \mathrm{a}$ \\
\hline Dizziness & N.S. & $\mathrm{n} / \mathrm{a}$ & $\mathrm{n} / \mathrm{a}$ & $\mathrm{n} / \mathrm{a}$ \\
\hline Over-sedation & Worse by ARP & $\mathrm{n} / \mathrm{a}$ & $\mathrm{n} / \mathrm{a}$ & $\mathrm{n} / \mathrm{a}$ \\
\hline Light-headedness & N.S. & $\mathrm{n} / \mathrm{a}$ & $\mathrm{n} / \mathrm{a}$ & $\mathrm{n} / \mathrm{a}$ \\
\hline Headache & N.S. & N.S. & N.S. & N.S. \\
\hline Fatigue & Worse by ARP & $\mathrm{n} / \mathrm{a}$ & $\mathrm{n} / \mathrm{a}$ & $\mathrm{n} / \mathrm{a}$ \\
\hline Insomnia & Worse by ARP & $\mathrm{n} / \mathrm{a}$ & $\mathrm{n} / \mathrm{a}$ & $\mathrm{n} / \mathrm{a}$ \\
\hline Pain extremities & Worse by ARP & $\mathrm{n} / \mathrm{a}$ & $\mathrm{n} / \mathrm{a}$ & $\mathrm{n} / \mathrm{a}$ \\
\hline EPS & Worse by ARP & $\mathrm{n} / \mathrm{a}$ & $\mathrm{n} / \mathrm{a}$ & N.S. \\
\hline Sialorrhea & Worse by ARP & $\mathrm{n} / \mathrm{a}$ & $\mathrm{n} / \mathrm{a}$ & $\mathrm{n} / \mathrm{a}$ \\
\hline Tremor & $\mathrm{n} / \mathrm{a}$ & $\mathrm{n} / \mathrm{a}$ & $\mathrm{n} / \mathrm{a}$ & N.S. \\
\hline URI & $\mathrm{n} / \mathrm{a}$ & N.S. & $\mathrm{n} / \mathrm{a}$ & $\mathrm{n} / \mathrm{a}$ \\
\hline
\end{tabular}

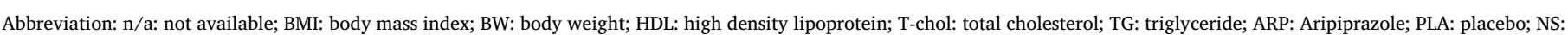
Non-significant difference; dis-side-effect Rates of discontinuation due to side effect; EPS: extrapyramidal symptoms; URI: upper respiratory-tract infection; Rx: medication. 
be considered with caution; however, aripiprazole has been approved for the treatment of $\mathrm{BD}$ in pediatric patients by the FDA in the USA and the EMA in the EU for its efficacy and safety. Furthermore, the previous two studies (Brown et al., 2013; Meduri et al., 2016) also included above two studies into their analyses. However, despite the apparent good tolerability, the results of this meta-analysis should be interpreted with caution for application in clinical practice in pediatric patients.

To differentiate the does-effect from primary outcome, we set the cutoff point of a higher and lower dose at $20 \mathrm{mg}$ /day. A previous metaanalysis (Brown et al., 2013) divided the enrolled trials into three groups at $10 \mathrm{mg} /$ day, $15 \mathrm{mg} /$ day, and $30 \mathrm{mg} /$ day. However, in order to include more trials in each group, we only divided them into two groups. Furthermore, an animal study (Li et al., 2004) demonstrated that a higher dose $(30 \mathrm{mg} / \mathrm{kg})$ in rodents could act as an antagonist to decrease cortical dopamine release, whereas a lower dose $(0.3 \mathrm{mg} / \mathrm{kg})$ would increase dopamine release in the medial prefrontal cortex and hippocampus. Setting a relatively higher cut-off point of $20 \mathrm{mg} /$ day could prevent the effect of dopamine agonism with aripiprazole, although no human trials have replicated this finding.

We summarized the efficacy of treating depression with aripiprazole. There was no significant difference in the efficacy between aripiprazole monotherapy and a placebo for acutely bipolar depression, although there was an insignificant trend favoring aripiprazole (effect size: $-0.127, p=0.054)$. However, its efficacy reached statistical significance when removing the study by Young et al. (Young et al., 2009) during the sensitivity test. This may be due to the relatively large sample $(n=320)$ compared to other studies $(n=272$ in Sachs et al.; 43 in Tramontina et al.; 296 in Findling et al. with three comparison arms). Furthermore, a relatively higher dropout rate $(43.1 \%)$ and discontinuation rate due to adverse reactions $(14.4 \%)$ may have excluded potential participants responsive to aripiprazole. A higher treatment dose of aripiprazole ( $>20 \mathrm{mg} /$ day) did not show increased efficacy (effect size: $-0.097, p=0.299$ ), although an insufficient number of trials with a lower treatment dose prevented further analysis. Of three previous meta-analyses (Fountoulakis et al., 2011; Meduri et al., 2016; Vieta et al., 2010), none showed positive results with the efficacy of aripiprazole at the endpoint; however, one study mentioned early efficacy for bipolar depression (Fountoulakis et al., 2011). Aripiprazole monotherapy did not significantly differ from haloperidol or lithium in the treatment efficacy of depressive symptoms during the acute phase, as assessed by reduced scores in the MADRS. In a short trial on combination therapy with aripiprazole in the acute stage, Quante et al. (2010) reported that aripiprazole plus citalopram was beneficial in treating bipolar depression compared to a placebo plus citalopram. These results may demonstrate the potential efficacy of aripiprazole in treating bipolar depression, and further studies focusing on bipolar depression may help to clarify the efficacy of aripiprazole.

For trials on mania with sufficient data for analysis, aripiprazole monotherapy was significantly superior to a placebo with a higher dose ( $>20 \mathrm{mg}$ /day), but not with a lower dose $(<20 \mathrm{mg} /$ day) or shorter treatment duration ( $<4$ weeks). From response and remission rates as secondary outcomes in the acute stage, aripiprazole was significantly better than a placebo. For sub-groups without enough trials to allow for analysis, one study with a longer treatment group ( $>4$ weeks) (Tramontina et al., 2009) and another trial (Vieta et al., 2008) reported that aripiprazole combination therapy in the acute stage showed significant efficacy. Previous systemic reviews and meta-analyses (Arbaizar et al., 2009; Brown et al., 2013; Fountoulakis et al., 2011; Meduri et al., 2016; Yildiz et al., 2015) reported significant efficacy in treating mania with aripiprazole, which is consistent with our results. Compared to the study focusing on mania (Brown et al., 2013), we used grouping to evaluate dose-dependent and time effects. As a result, our results suggest that a higher dose ( $>20 \mathrm{mg} /$ day) and longer treatment period ( $>4$ weeks) may achieve better outcomes for bipolar mania, although previous publications (Dhillon, 2012; Schatzberg and Nemeroff, 2009) suggested that a therapeutic dose of 15 to $30 \mathrm{mg}$ /day may be appropriate for bipolar mania. In comparisons of aripiprazole monotherapy versus a placebo in acute mania, our meta-regression revealed that an older age was associated with a poorer outcome with aripiprazole treatment than with a placebo with a significant but relatively small effective coefficient ratio (coefficient $=0.0137$, $p=0.0081$ ). A previous study investigating predictors for recovery from mania showed that an older age was associated with a faster recovery from mania (Tohen et al., 2003), although this may be not meaningful for our results due to the relatively small effect size.

Few studies (Fountoulakis et al., 2011) have investigated relapse rates under aripiprazole treatment for $\mathrm{BD}$. We focused on the relapse rates as preventive efficacy within acute or maintenance states. No significance differences in relapse rates were observed between aripiprazole monotherapy and a placebo in the acute stage of $\mathrm{BD}$, however, combination aripiprazole therapy showed a better preventive effect as measured by relapse rates (OR: $0.522, p=0.029$ ) versus a placebo in the maintenance stage of $\mathrm{BD}$. Although there were insufficient trials to allow for subgroup analysis of aripiprazole monotherapy versus a placebo in maintenance therapy, both studies (Keck et al., 2009; Muzina et al., 2008) showed promising efficacy of aripiprazole. Therefore, it may be more appropriate to use relapse rates as the primary outcome in the maintenance phase than in the acute phase in clinical practice, because the maintenance phase has a longer period of follow-up than the acute phase. Furthermore, our results differ from a previous meta-analysis (Miura et al., 2014) which demonstrated no significant efficacy in relapse rates in the maintenance state of BD. In summary, the current study clarifies the efficacy of relapse rates, and suggests that they can be applied to clinical practice in the future.

We also analyzed the CGI-S as an alternative measurement of efficacy of aripiprazole treatment. Comparing aripiprazole monotherapy and a placebo in the acute stage of BD, aripiprazole was associated with significant improvements in the CGI-S than a placebo across manic/ mixed and depressed states, and also with aripiprazole monotherapy and a placebo in the maintenance stage. These results are comparable to previous studies (Brown et al., 2013; Fountoulakis et al., 2011) which reported categories of CGI, however further clinical trials are necessary for subgroup analysis within different categories of mood state. In three trials (Keck et al., 2009; Vieta et al., 2005; Young et al., 2009), aripiprazole was significantly better than other medications (haloperidol or lithium) in the CGI-S (effect size: $-0.191, p=0.003$ ) with regards to treatment efficacy of $\mathrm{BD}$ during the acute phase. In addition, the efficacy of treatment for psychotic features is also important due to the effect on recovery in BD. Psychotic mania has been associated with longer periods of remission (Rosenthal et al., 1979), higher rates of relapse, worse social functioning, and occupational status (Tohen et al., 1990) compared to non-psychotic mania. Moreover, psychotic features are highly associated with suicide attempts in patients with BD (McGrady et al., 2017). Aripiprazole monotherapy tended to reduce PANSS scores compared to a placebo in the acute phase, indicating a beneficial effect in treating psychotic features. Another meta-analysis (Fountoulakis et al., 2009) also supports the usefulness of aripiprazole for psychotic symptoms during the acute manic and maintenance phases of $\mathrm{BD}$, which is consistent with our results.

Antipsychotic medications are associated with a wide range of potential adverse effects, including metabolic syndrome. A populationbased cohort study (Chien et al., 2010) found that the use of antipsychotics was hazardous for patients with BD suffering from diabetes. We comprehensively analyzed associations between aripiprazole and the metabolic syndrome/diabetes. Compared to a placebo in the acute phase, aripiprazole was significantly associated with a lower risk of elevated fasting glucose, increased appetite, and level of total cholesterol. No significant differences in levels of HDL, TG, BMI or body weight were found. In the maintenance stage of $\mathrm{BD}$, aripiprazole was still not associated with significant differences in fasting glucose, increased body weight, level of total cholesterol, or level of TG. Of note, aripiprazole was associated with a significantly higher level of HDL 
than a placebo (effect size: $-0.710, p=0.002$ ) with a mean increment of $2.662 \mathrm{mg} / \mathrm{dl}$ after aripiprazole treatment. HDL has been shown to be beneficial as a cardiovascular protector (Gomaraschi et al., 2016) and to exert anti-diabetogenic functions on beta cells of the endocrine pancreas (von Eckardstein and Widmann, 2014). In combination therapy, aripiprazole was associated with lower levels of fasting glucose and TG, and a smaller increase in body weight than a placebo. However, a significant increase in total cholesterol of $2 \mathrm{mg} / \mathrm{dl}$ was found in the aripiprazole group compared with a placebo. Considering the normal ranges of total cholesterol $(<200 \mathrm{mg} / \mathrm{dl})$ and HDL $(40-60 \mathrm{mg}$ / $\mathrm{dl}$ ), an increase in total cholesterol of $2 \mathrm{mg} / \mathrm{dl}$ may not be clinically meaningful. In conclusion, aripiprazole seems to be a safe therapeutic option with regards to metabolic profile. We then evaluated possibly associations between gastro-intestinal disturbances and aripiprazole treatment (Taylor, 2003) with regards to short-term nausea, vomiting, and constipation. Our result showed that aripiprazole should be used cautiously due to gastro-intestinal problems. In the acute stage, aripiprazole was significantly associated with higher rates of constipation, nausea, and vomiting than a placebo, although no harmful cases of diarrhea or dyspepsia were observed. When extending the follow-up period to the maintenance stage, aripiprazole continued to be associated with a higher incidence of diarrhea and dry mouth than a placebo. Our findings are inconsistent with a previous study (Brown et al., 2013), which suggested insignificant differences of rate of diarrhea compared to placebo, and clinicians should carefully explain these side effects before prescribing aripiprazole to patients with BD.

EPS is an undesirable adverse reaction to all antipsychotics, although atypical antipsychotics may have a lower risk than typical antipsychotics (Pierre, 2005). Aripiprazole was associated with a significantly higher incidence of EPS and hyper-salivation in the acute phase than a placebo. However, there were no significant differences in EPS among the patients receiving aripiprazole monotherapy and other medications (haloperidol or lithium). Specifically, aripiprazole was better than haloperidol, but not different than lithium. No significance differences were noted in tremors between haloperidol or lithium. Hence, aripiprazole may be beneficial compared to other medications, which is consistent with the findings of a previous meta-analysis (Brown et al., 2013) focusing on bipolar mania. Moreover, other undesirable symptoms including anxiety and akathisia should be addressed due to the high incidence of akathisia in several trials (El Mallakh et al., 2010; Thase et al., 2008). Aripiprazole was associated with higher rates of akathisia and anxiety than a placebo in the acute stage, and a higher rate of akathisia in the maintenance stage. However, compared to other medications (lithium or haloperidol), there was no significant difference in akathisia (effect size: $-0.130, p=0.696$ ). Therefore, aripiprazole may not be as hazardous as previously thought, and further clinical trials are warranted to investigate this issue, especially for comparisons with anticonvulsants or other second-generation antipsychotics.

For other adverse reactions including, dizziness, agitation, headache, light headedness, and upper respiratory tract infection, there were no significant differences between aripiprazole and a placebo in the acute or maintenance stage. However, aripiprazole was associated with significantly higher incidence rates of fatigue, insomnia, over-sedation, and pain in the extremities compared to a placebo. However, there was no significant difference in over-sedation between aripiprazole and a placebo in the maintenance phase. There was also no significant difference in the incidence of headache between aripiprazole and haloperidol or lithium. We assessed adherence using dropout rates and rates of discontinuation due to side effects. Compared with a placebo in the acute stage, no significance was noted for aripiprazole in dropout rate, however there was a significantly lower dropout rate with aripiprazole in the maintenance stage. In combination therapy, there was no significant difference between aripiprazole and a placebo in dropout rate. The results of recent meta-analyses (Brown et al., 2013; Meduri et al., 2016; Yildiz et al., 2015) are consistent with our findings with regards to drop-out rates. However, aripiprazole was associated with a higher rate of discontinuation due to side effects than a placebo in acute and maintenance stages, which may have been due to the relatively higher incidence of intolerable side effects such as akathisia and gastro-intestinal disturbances. However, there were no significant differences in discontinuation rates due to side effects between aripiprazole and lithium or haloperidol, which is consistent with the study by Brown et al. (2013). Our results suggest that aripiprazole may not be more hazardous than other medications.

A strength of the current study is that we focused our analysis on aripiprazole treatment across mania to depression in BD. Our results show inconsistencies in the efficacy or adverse reactions of aripiprazole treatment, which is also a strength.

\section{Limitations}

There are several limitations to this study. First, the lack of trials (fewer than three) for subgroup analysis, including aripiprazole monotherapy versus other medications in the maintenance stage, aripiprazole combination therapy versus other medications in the acute and maintenance stages, and aripiprazole combination therapy versus a placebo in the acute stage, limits the strength of our results. Second, due to language limitations, we may have missed articles published in other languages. Third, we cannot rule out the possible confounding effects of the concomitant use of other medications with combination therapy of aripiprazole and a placebo/other medications. Fourth, due to the limited number of included studies, we could not undertake meaningful meta-regression analyses of specific comparison groups (maintenance stage, etc.) to investigate the influence of variables that may have influenced the observed results and the heterogeneity of these findings. Finally, due to the absence of head to head studies considering the advantages or disadvantages of aripiprazole over other secondgeneration antipsychotics, we could not perform meta-analyses between them, which may be a concern in clinical practice.

\section{Conclusion}

In summary, the current meta-analysis adds to the current knowledge on treating bipolar mania, especially with regards to secondary outcomes and safety profiles. Our results showed that aripiprazole was beneficial in preventing bipolar mania. Unfortunately, aripiprazole has a minimal effect on bipolar depression. In addition, aripiprazole has outstanding tolerability with regards to the metabolic syndrome, EPS, and dropout rates. Furthermore, aripiprazole may be beneficial in clinical practice for akathisia compared to haloperidol or lithium, although it was more hazardous than a placebo. Caution should be taken with regards to gastro-intestinal disturbances when prescribing aripiprazole. Future trials should carefully detail information on the incidence of adverse events and treatment efficacy compared to other medications, especially second-generation antipsychotics.

Supplementary data to this article can be found online at http://dx. doi.org/10.1016/j.pnpbp.2017.06.023.

\section{Conflict of interest}

One of the first author, Ping-Tao, Tseng had ever received speaker fees by the Otsuka for the seminar of aripiprazole. Dr. Eduard Vieta has received grants and served as consultant, advisor or speaker for the following entities: AB-Biotics, Almirall, Allergan, AstraZeneca, BristolMyers Squibb, Cephalon, Dainippon Sumitomo Pharma, Elan, Eli Lilly, Farmindustria, Ferrer, Forest Research Institute, Gedeon Richter, GlaxoSmithKline, Janssen, Jazz, Johnson and Johnson, Lundbeck, Merck, Novartis, Organon, Otsuka, Pfizer, Roche, Sanofi-Aventis, Servier, Schering-Plough, Shire, the Brain and Behavior Foundation, the Seventh European Framework Programme (ENBREC), the Stanley Medical Research Institute, Sunovion, Takeda, Teva, and United 
BioSource Corporation. All other authors declare no biomedical conflicts of interest. 2016

Part of current meta-analysis had been orally presented in PRCP

\section{Acknowledgments}

There was no research funding for this work.

\section{References}

Angst, J., 2006. Do many patients with depression suffer from bipolar disorder? Can. J. Psychiatr. 51 (1), 3-5.

Arbaizar, B., Dierssen-Sotos, T., Gomez-Acebo, I., Llorca, J., 2009. Aripiprazole in major depression and mania: meta-analyses of randomized placebo-controlled trials. Gen. Hosp. Psychiatry 31 (5), 478-483.

Biederman, J., McDonnell, M.A., Wozniak, J., Spencer, T., Aleardi, M., Falzone, R., Mick, E., 2005. Aripiprazole in the treatment of pediatric bipolar disorder: a systematic chart review. CNS Spectr. 10 (2), 141-148.

Borenstein, M., Hedges, L.V., Higgins, J.P., Rothstein, H.R., 2010. A basic introduction to fixed-effect and random-effects models for meta-analysis. Res. Synth. Methods 1 (2), 97-111.

Brown, R., Taylor, M.J., Geddes, J., 2013. Aripiprazole alone or in combination for acute mania. Cochrane Database Syst. Rev. 12, CD005000.

Burris, K.D., Molski, T.F., Xu, C., Ryan, E., Tottori, K., Kikuchi, T., Yocca, F.D., Molinoff, P.B., 2002. Aripiprazole, a novel antipsychotic, is a high-affinity partial agonist at human dopamine D2 receptors. J. Pharmacol. Exp. Ther. 302 (1), 381-389.

Busner, J., Targum, S.D., 2007. The clinical global impressions scale: applying a research tool in clinical practice. Psychiatry (Edgmont) 4 (7), 28-37.

Carlson, B.X., Ketter, T.A., Sun, W., Timko, K., McQuade, R.D., Sanchez, R., VesterBlokland, E., Marcus, R., 2012. Aripiprazole in combination with lamotrigine for the long-term treatment of patients with bipolar I disorder (manic or mixed): a randomized, multicenter, double-blind study (CN138-392). Bipolar Disord. 14 (1), 41-53.

Chien, I.C., Chang, K.C., Lin, C.H., Chou, Y.J., Chou, P., 2010. Prevalence of diabetes in patients with bipolar disorder in Taiwan: a population-based national health insurance study. Gen. Hosp. Psychiatry 32 (6), 577-582.

Craddock, N., Sklar, P., 2013. Genetics of bipolar disorder. Lancet 381 (9878), 1654-1662.

Davey, J., Turner, R.M., Clarke, M.J., Higgins, J.P., 2011. Characteristics of meta-analyses and their component studies in the cochrane database of systematic reviews: a crosssectional, descriptive analysis. BMC Med. Res. Methodol. 11, 160.

Dhillon, S., 2012. Aripiprazole: a review of its use in the management of mania in adults with bipolar I disorder. Drugs 72 (1), 133-162.

Dundar, Y., Greenhalgh, J., Richardson, M., Dwan, K., 2016. Pharmacological treatment of acute agitation associated with psychotic and bipolar disorder: a systematic review and meta-analysis. Hum. Psychopharmacol. 31 (4), 268-285.

Duval, S., Tweedie, R., 2000. Trim and fill: a simple funnel-plot-based method of testing and adjusting for publication bias in meta-analysis. Biometrics 56 (2), 455-463.

von Eckardstein, A., Widmann, C., 2014. High-density lipoprotein, beta cells, and diabetes. Cardiovasc. Res. 103 (3), 384-394.

Egger, M., Davey Smith, G., Schneider, M., Minder, C., 1997. Bias in meta-analysis detected by a simple, graphical test. BMJ 315 (7109), 629-634.

El Mallakh, R.S., Vieta, E., Rollin, L., Marcus, R., Carson, W.H., McQuade, R., 2010. A comparison of two fixed doses of aripiprazole with placebo in acutely relapsed, hospitalized patients with bipolar disorder I (manic or mixed) in subpopulations (CN138-007). Eur. Neuropsychopharmacol. 20 (11), 776-783.

El-Mallakh, R.S., Marcus, R., Baudelet, C., McQuade, R., Carson, W.H., Owen, R., 2012. A 40-week double-blind aripiprazole versus lithium follow-up of a 12-week acute phase study (total 52 weeks) in bipolar I disorder. J. Affect. Disord. 136 (3), 258-266.

Findling, R.L., Nyilas, M., Forbes, R.A., McQuade, R.D., Jin, N., Iwamoto, T., Ivanova, S., Carson, W.H., Chang, K., 2009. Acute treatment of pediatric bipolar I disorder, manic or mixed episode, with aripiprazole: a randomized, double-blind, placebo-controlled study. J. Clin. Psychiatry 70 (10), 1441-1451.

Findling, R.L., Youngstrom, E.A., McNamara, N.K., Stansbrey, R.J., Wynbrandt, J.L., Adegbite, C., Rowles, B.M., Demeter, C.A., Frazier, T.W., Calabrese, J.R., 2012. Double-blind, randomized, placebo-controlled long-term maintenance study of aripiprazole in children with bipolar disorder. J. Clin. Psychiatry 73 (1), 57-63.

Findling, R.L., Correll, C.U., Nyilas, M., Forbes, R.A., McQuade, R.D., Jin, N., Ivanova, S., Mankoski, R., Carson, W.H., Carlson, G.A., 2013. Aripiprazole for the treatment of pediatric bipolar I disorder: a 30-week, randomized, placebo-controlled study. Bipolar Disord. 15 (2), 138-149.

Fountoulakis, K.N., Gonda, X., Vieta, E., Schmidt, F., 2009. Treatment of psychotic symptoms in bipolar disorder with aripiprazole monotherapy: a meta-analysis. Ann. General Psychiatry 8, 27.

Fountoulakis, K.N., Vieta, E., Schmidt, F., 2011. Aripiprazole monotherapy in the treatment of bipolar disorder: a meta-analysis. J. Affect. Disord. 133 (3), 361-370.

Gomaraschi, M., Calabresi, L., Franceschini, G., 2016. Protective effects of HDL against ischemia/reperfusion injury. Front. Pharmacol. 7, 2.

Goodwin, G.M., Anderson, I., Arango, C., Bowden, C.L., Henry, C., Mitchell, P.B., Nolen, W.A., Vieta, E., Wittchen, H.U., 2008. ECNP consensus meeting. Bipolar depression. Nice, March 2007. Eur. Neuropsychopharmacol. 18 (7), 535-549.

Goodwin, G.M., Haddad, P.M., Ferrier, I.N., Aronson, J.K., Barnes, T., Cipriani, A.,
Coghill, D.R., Fazel, S., Geddes, J.R., Grunze, H., Holmes, E.A., Howes, O., Hudson, S., Hunt, N., Jones, I., Macmillan, I.C., McAllister-Williams, H., Miklowitz, D.R., Morriss, R., Munafo, M., Paton, C., Saharkian, B.J., Saunders, K., Sinclair, J., Taylor, D., Vieta, E., Young, A.H., 2016. Evidence-based guidelines for treating bipolar disorder: revised third edition recommendations from the British Association for Psychopharmacology. J. Psychopharmacol. 30 (6), 495-553.

Higgins, J.P., Thompson, S.G., Deeks, J.J., Altman, D.G., 2003. Measuring inconsistency in meta-analyses. BMJ 327 (7414), 557-560.

Hirschfeld, R.M., Lewis, L., Vornik, L.A., 2003. Perceptions and impact of bipolar disorder: how far have we really come? Results of the national depressive and manicdepressive association 2000 survey of individuals with bipolar disorder. J. Clin. Psychiatry 64 (2), 161-174.

Jadad, A.R., Moore, R.A., Carroll, D., Jenkinson, C., Reynolds, D.J., Gavaghan, D.J., McQuay, H.J., 1996. Assessing the quality of reports of randomized clinical trials: is blinding necessary? Control. Clin. Trials 17 (1), 1-12.

Jeong, H.G., Lee, M.S., Ko, Y.H., Han, C., Jung, I.K., 2012. Combination treatment with aripiprazole and valproic acid for acute mania: an 8-week, single-blind, randomized controlled trial. Clin. Neuropharmacol. 35 (3), 97-102.

Jordan, S., Koprivica, V., Chen, R., Tottori, K., Kikuchi, T., Altar, C.A., 2002. The antipsychotic aripiprazole is a potent, partial agonist at the human 5-HT1A receptor. Eur. J. Pharmacol. 441 (3), 137-140.

Judd, L.L., Akiskal, H.S., 2003. The prevalence and disability of bipolar spectrum disorders in the US population: re-analysis of the ECA database taking into account subthreshold cases. J. Affect. Disord. 73 (1-2), 123-131.

Kanba, S., Kawasaki, H., Ishigooka, J., Sakamoto, K., Kinoshita, T., Kuroki, T., 2014. A placebo-controlled, double-blind study of the efficacy and safety of aripiprazole for the treatment of acute manic or mixed episodes in Asian patients with bipolar I disorder (the AMAZE study). World J. Biol. Psychiatry 15 (2), 113-121.

Kattimani, S., Subramanian, K., Sarkar, S., Rajkumar, R.P., Balasubramanian, S., 2016. History of lifetime suicide attempt in bipolar I disorder: its correlates and effect on illness course. Int. J. Psychiatry Clin. Pract. 1-7.

Kay, S.R., Fiszbein, A., Opler, L.A., 1987. The positive and negative syndrome scale (PANSS) for schizophrenia. Schizophr. Bull. 13 (2), 261-276.

Keck Jr., P.E., Marcus, R., Tourkodimitris, S., Ali, M., Liebeskind, A., Saha, A., Ingenito G., Aripiprazole Study, G., 2003. A placebo-controlled, double-blind study of the efficacy and safety of aripiprazole in patients with acute bipolar mania. Am. J. Psychiatry 160 (9), 1651-1658.

Keck Jr., P.E., Calabrese, J.R., McIntyre, R.S., McQuade, R.D., Carson, W.H., Eudicone, J.M., Carlson, B.X., Marcus, R.N., Sanchez, R., Aripiprazole Study, G., 2007. Aripiprazole monotherapy for maintenance therapy in bipolar I disorder: a 100-week, double-blind study versus placebo. J. Clin. Psychiatry 68 (10), 1480-1491.

Keck, P.E., Orsulak, P.J., Cutler, A.J., Sanchez, R., Torbeyns, A., Marcus, R.N., McQuade, R.D., Carson, W.H., Group, C.N.S, 2009. Aripiprazole monotherapy in the treatment of acute bipolar I mania: a randomized, double-blind, placebo- and lithium-controlled study. J. Affect. Disord. 112 (1-3), 36-49.

Li, Z., Ichikawa, J., Dai, J., Meltzer, H.Y., 2004. Aripiprazole, a novel antipsychotic drug, preferentially increases dopamine release in the prefrontal cortex and hippocampus in rat brain. Eur. J. Pharmacol. 493 (1-3), 75-83.

Liberati, A., Altman, D.G., Tetzlaff, J., Mulrow, C., Gotzsche, P.C., Ioannidis, J.P., Clarke, M., Devereaux, P.J., Kleijnen, J., Moher, D., 2009. The PRISMA statement for reporting systematic reviews and meta-analyses of studies that evaluate health care interventions: explanation and elaboration. PLoS Med. 6 (7), e1000100.

Lindstrom, L., Lindstrom, E., Nilsson, M., Hoistad, M., 2017. Maintenance therapy with second generation antipsychotics for bipolar disorder - a systematic review and metaanalysis. J. Affect. Disord. 213, 138-150.

van der Loos, M.L., Mulder, P., Hartong, E.G., Blom, M.B., Vergouwen, A.C., van Noorden, M.S., Timmermans, M.A., Vieta, E., Nolen, W.A., LamLit Study, G, 2011. Long-term outcome of bipolar depressed patients receiving lamotrigine as add-on to lithium with the possibility of the addition of paroxetine in nonresponders: a randomized, placebo-controlled trial with a novel design. Bipolar Disord. 13 (1), 111-117.

Marcus, R., Khan, A., Rollin, L., Morris, B., Timko, K., Carson, W., Sanchez, R., 2011. Efficacy of aripiprazole adjunctive to lithium or valproate in the long-term treatment of patients with bipolar I disorder with an inadequate response to lithium or valproate monotherapy: a multicenter, double-blind, randomized study. Bipolar Disord. 13 (2), 133-144.

McGrady, A., Lynch, D., Rapport, D., 2017. Psychosocial factors and comorbidity associated with suicide attempts: findings in patients with bipolar disorder. Psychopathology.

McKeage, K., 2014. Aripiprazole: a review of its use in the treatment of manic episodes in adolescents with bipolar I disorder. CNS Drugs 28 (2), 171-183.

Meduri, M., Gregoraci, G., Baglivo, V., Balestrieri, M., Isola, M., Brambilla, P., 2016. A meta-analysis of efficacy and safety of aripiprazole in adult and pediatric bipolar disorder in randomized controlled trials and observational studies. J. Affect. Disord. 191, 187-208.

Merikangas, K.R., Jin, R., He, J.P., Kessler, R.C., Lee, S., Sampson, N.A., Viana, M.C., Andrade, L.H., Hu, C., Karam, E.G., Ladea, M., Medina-Mora, M.E., Ono, Y., PosadaVilla, J., Sagar, R., Wells, J.E., Zarkov, Z., 2011. Prevalence and correlates of bipolar spectrum disorder in the world mental health survey initiative. Arch. Gen. Psychiatry 68 (3), 241-251.

Miura, T., Noma, H., Furukawa, T.A., Mitsuyasu, H., Tanaka, S., Stockton, S., Salanti, G., Motomura, K., Shimano-Katsuki, S., Leucht, S., Cipriani, A., Geddes, J.R., Kanba, S. 2014. Comparative efficacy and tolerability of pharmacological treatments in the maintenance treatment of bipolar disorder: a systematic review and network metaanalysis. Lancet Psychiatry 1 (5), 351-359.

Montgomery, S.A., Asberg, M., 1979. A new depression scale designed to be sensitive to change. Br. J. Psychiatry 134, 382-389. 
Muzina, D.J., Momah, C., Eudicone, J.M., Pikalov, A., McQuade, R.D., Marcus, R.N., Sanchez, R., Carlson, B.X., 2008. Aripiprazole monotherapy in patients with rapidcycling bipolar I disorder: an analysis from a long-term, double-blind, placebo-controlled study. Int. J. Clin. Pract. 62 (5), 679-687.

Nilsson, K.K., Jorgensen, C.R., Craig, T.K., Straarup, K.N., Licht, R.W., 2010. Self-esteem in remitted bipolar disorder patients: a meta-analysis. Bipolar Disord. 12 (6), $585-592$

Oud, M., Mayo-Wilson, E., Braidwood, R., Schulte, P., Jones, S.H., Morriss, R., Kupka, R., Cuijpers, P., Kendall, T., 2016. Psychological interventions for adults with bipolar disorder: systematic review and meta-analysis. Br. J. Psychiatry 208 (3), 213-222.

Oya, K., Kishi, T., Iwata, N., 2015. Efficacy and tolerability of aripiprazole once monthly for schizophrenia: a systematic review and meta-analysis of randomized controlled trials. Neuropsychiatr. Dis. Treat. 11, 2299-2307.

Perlis, R.H., 2007. Treatment of bipolar disorder: the evolving role of atypical antipsychotics. Am. J. Manag. Care 13 (7 Suppl), S178-S188.

Perlis, R.H., Welge, J.A., Vornik, L.A., Hirschfeld, R.M., Keck Jr., P.E., 2006. Atypical antipsychotics in the treatment of mania: a meta-analysis of randomized, placebocontrolled trials. J. Clin. Psychiatry 67 (4), 509-516.

Pierre, J.M., 2005. Extrapyramidal symptoms with atypical antipsychotics: incidence, prevention and management. Drug Saf. 28 (3), 191-208.

Quante, A., Zeugmann, S., Luborzewski, A., Schommer, N., Langosch, J., Born, C., Anghelescu, I., Wolf, J., 2010. Aripiprazole as adjunct to a mood stabilizer and citalopram in bipolar depression: a randomized placebo-controlled pilot study. Hum. Psychopharmacol. 25 (2), 126-132.

Reed, C., Goetz, I., Vieta, E., Bassi, M., Haro, J.M., Board, E.A., 2010. Work impairment in bipolar disorder patients-results from a two-year observational study (EMBLEM). Eur. Psychiatry 25 (6), 338-344.

Rosenthal, N.E., Rosenthal, L.N., Stallone, F., Fleiss, J., Dunner, D.L., Fieve, R.R., 1979. Psychosis as a predictor of response to lithium maintenance treatment in bipolar affective disorder. J. Affect. Disord. 1 (4), 237-245.

Sachs, G., Sanchez, R., Marcus, R., Stock, E., McQuade, R., Carson, W., Abou-Gharbia, N., Impellizzeri, C., Kaplita, S., Rollin, L., Iwamoto, T., Aripiprazole Study, G., 2006. Aripiprazole in the treatment of acute manic or mixed episodes in patients with bipolar I disorder: a 3-week placebo-controlled study. J. Psychopharmacol. 20 (4), $536-546$.

Schatzberg, A.F., Nemeroff, C.B., 2009. The American Psychiatric Publishing Textbook of Psychopharmacology, 4th ed. American Psychiatric Pub, Washington, D.C.

Scherk, H., Pajonk, F.G., Leucht, S., 2007. Second-generation antipsychotic agents in the treatment of acute mania: a systematic review and meta-analysis of randomized controlled trials. Arch. Gen. Psychiatry 64 (4), 442-455.

Smith, L.A., Cornelius, V., Warnock, A., Tacchi, M.J., Taylor, D., 2007. Pharmacological interventions for acute bipolar mania: a systematic review of randomized placebocontrolled trials. Bipolar Disord. 9 (6), 551-560.

Taylor, D.M., 2003. Aripiprazole: a review of its pharmacology and clinical use. Int. J. Clin. Pract. 57 (1), 49-54.

Thase, M.E., Jonas, A., Khan, A., Bowden, C.L., Wu, X., McQuade, R.D., Carson, W.H., Marcus, R.N., Owen, R., 2008. Aripiprazole monotherapy in nonpsychotic bipolar I depression: results of 2 randomized, placebo-controlled studies. J. Clin. Psychopharmacol. 28 (1), 13-20.

Tohen, M., Waternaux, C.M., Tsuang, M.T., 1990. Outcome in Mania. A 4-year prospective follow-up of 75 patients utilizing survival analysis. Arch. Gen. Psychiatry 47 (12), 1106-1111.

Tohen, M., Zarate Jr., C.A., Hennen, J., Khalsa, H.M., Strakowski, S.M., Gebre-Medhin, P., Salvatore, P., Baldessarini, R.J., 2003. The McLean-Harvard first-episode mania study: prediction of recovery and first recurrence. Am. J. Psychiatry 160 (12),
2099-2107.

Tramontina, S., Zeni, C.P., Ketzer, C.R., Pheula, G.F., Narvaez, J., Rohde, L.A., 2009 Aripiprazole in children and adolescents with bipolar disorder comorbid with attention-deficit/hyperactivity disorder: a pilot randomized clinical trial. J. Clin. Psychiatry 70 (5), 756-764.

Vancampfort, D., Stubbs, B., Mitchell, A.J., De Hert, M., Wampers, M., Ward, P.B., Rosenbaum, S., Correll, C.U., 2015. Risk of metabolic syndrome and its components in people with schizophrenia and related psychotic disorders, bipolar disorder and major depressive disorder: a systematic review and meta-analysis. World Psychiatry 14 (3), 339-347.

Vancampfort, D., Correll, C.U., Galling, B., Probst, M., De Hert, M., Ward, P.B., Rosenbaum, S., Gaughran, F., Lally, J., Stubbs, B., 2016. Diabetes mellitus in people with schizophrenia, bipolar disorder and major depressive disorder: a systematic review and large scale meta-analysis. World Psychiatry 15 (2), 166-174.

Vieta, E., Bourin, M., Sanchez, R., Marcus, R., Stock, E., McQuade, R., Carson, W., AbouGharbia, N., Swanink, R., Iwamoto, T., Aripoprazole Study, G., 2005. Effectiveness of aripiprazole v. haloperidol in acute bipolar mania: double-blind, randomised, comparative 12-week trial. Br. J. Psychiatry 187, 235-242.

Vieta, E., T'Joen, C., McQuade, R.D., Carson Jr., W.H., Marcus, R.N., Sanchez, R., Owen, R., Nameche, L., 2008. Efficacy of adjunctive aripiprazole to either valproate or lithium in bipolar mania patients partially nonresponsive to valproate/lithium monotherapy: a placebo-controlled study. Am. J. Psychiatry 165 (10), 1316-1325.

Vieta, E., Locklear, J., Gunther, O., Ekman, M., Miltenburger, C., Chatterton, M.L., Astrom, M., Paulsson, B., 2010. Treatment options for bipolar depression: a systematic review of randomized, controlled trials. J. Clin. Psychopharmacol. 30 (5), $579-590$.

Williams, J.B., 1988. A structured interview guide for the Hamilton Depression Rating Scale. Arch. Gen. Psychiatry 45 (8), 742-747.

Woo, Y.S., Bahk, W.M., Chung, M.Y., Kim, D.H., Yoon, B.H., Lee, J.H., Ahn, Y.M., Chung, S.K., Kim, J.G., Lee, K.H., Paik, K.C., 2011. Aripiprazole plus divalproex for recently manic or mixed patients with bipolar I disorder: a 6-month, randomized, placebocontrolled, double-blind maintenance trial. Hum. Psychopharmacol. 26 (8), 543-553.

Yatham, L.N., Lecrubier, Y., Fieve, R.R., Davis, K.H., Harris, S.D., Krishnan, A.A., 2004. Quality of life in patients with bipolar I depression: data from 920 patients. Bipolar Disord. 6 (5), 379-385.

Yatham, L.N., Kennedy, S.H., Parikh, S.V., Schaffer, A., Beaulieu, S., Alda, M., O'Donovan, C., Macqueen, G., McIntyre, R.S., Sharma, V., Ravindran, A., Young, L.T., Milev, R., Bond, D.J., Frey, B.N., Goldstein, B.I., Lafer, B., Birmaher, B., Ha, K., Nolen, W.A., Berk, M., 2013. Canadian Network for Mood and Anxiety Treatments (CANMAT) and International Society for Bipolar Disorders (ISBD) collaborative update of CANMAT guidelines for the management of patients with bipolar disorder: update 2013. Bipolar Disord. 15 (1), 1-44.

Yildiz, A., Vieta, E., Leucht, S., Baldessarini, R.J., 2011. Efficacy of antimanic treatments: meta-analysis of randomized, controlled trials. Neuropsychopharmacology 36 (2), 375-389.

Yildiz, A., Nikodem, M., Vieta, E., Correll, C.U., Baldessarini, R.J., 2015. A network metaanalysis on comparative efficacy and all-cause discontinuation of antimanic treatments in acute bipolar mania. Psychol. Med. 45 (2), 299-317.

Young, R.C., Biggs, J.T., Ziegler, V.E., Meyer, D.A., 1978. A rating scale for mania: reliability, validity and sensitivity. Br. J. Psychiatry 133, 429-435.

Young, A.H., Oren, D.A., Lowy, A., McQuade, R.D., Marcus, R.N., Carson, W.H., Spiller, N.H., Torbeyns, A.F., Sanchez, R., 2009. Aripiprazole monotherapy in acute mania: 12-week randomised placebo- and haloperidol-controlled study. Br. J. Psychiatry 194 (1), 40-48. 